\title{
Mass Spectrometric Analysis of Nitrogen- and Phosphorus-Containing Pesticides by Liquid Chromatography-Mass Spectrometry
}

\author{
Dietrich Volmer and Karsten Levsen \\ Department of Analytical Chemistry, Fraunhofer Institute of Toxicology and Aerosol Research, \\ Hannover, Germany
}

\begin{abstract}
A series of nitrogen- and phosphorus-containing pesticides (amines, anilides, carbamates, phosphonates, phenylureas, sulfonylureas, and triazines) was examined by thermospray (TSP) ionization. A method is described that employs off-line and on-line solid-phase extraction and TSP liquid chromatography-mass spectrometry (LC-MS) with time-scheduled selected ion monitoring (SIM) for environmental monitoring of these pesticides in aqueous samples. SIM detection limits for the pesticides analyzed in conjunction with reversed-phase high-performance liquid chromatography range from 40 to $600 \mathrm{pg}$. In addition, methods for inducing fragmentation in thermospray LC-MS are presented. The structural information gained therefrom can be used to confirm a tentative identification. Therefore, fragmentation pathways under certain experimental conditions were investigated. Atmospheric pressure chemical ionization, electrospray, fast-atom bombardment, ${ }^{252} \mathrm{Cf}$ plasma desorption, and collision-activated dissociation spectra are presented for several pesticides to confirm the proposed pathways and to gain additional and complementary information. Further confirmation may be achieved by postcolumn addition of different alkylated amines to the carrier stream in the TSP operation to induce postcolumn on-line derivatization (POD) reactions in the condensed phase of the vaporizer probe with selected pesticides. Additional clustering reactions in combination with solvent-mediated chemical ionization are observed by the POD technique. Both processes can be used to enhance the structural information from TSP spectra and thus the specificity of the method. (J Am Soc Mass Spectrom 1994, 5, 655-675)
\end{abstract}

$\mathrm{T}$ The National Survey of Pesticides in Ground Water [1] published by the U.S. Environmental Protection Agency (EPA) lists 126 polar compounds as potential groundwater contaminants. Although the EPA does not prescribe limit values for these compounds, the Commission of the European Communities (CEC) [2] has set maximum admissible concentrations for pesticides in drinking water $\left(100 \mathrm{ng} \mathrm{L}^{-1}\right.$ of an individual pesticide and $500 \mathrm{ng} \mathrm{\textrm {L } ^ { - 1 }}$ for the sum of all pesticides). For the verification of these limits, universal methods are required that allow the determination of as many as possible of the relevant agents, preferably within one common method.

Gas chromatography (GC) is the traditional method for the analysis of pesticides. The widespread use of GC mass spectrometry is due to the existence of reliable, specific, and sensitive methods for analyzing hundreds of organic compounds including many pesticides in several matrices. However, pesticides amen-

Address reprint requests to Dietrich Volmer. Fraunhofer Institute of Toxicology and Aerosol Research, Nikolai-Fuchs-Strasse 1, D-30625 Hannover, Germany. able to GC are restricted to those with low polarity and sufficient voliatility. Several techniques are available to convert at least a limited number of nonvolatile compounds to derivatives amenable to GC. Searching for new derivatization procedures is not attractive because these methods are time-consuming and rarely can be incorporated into a universal method for a wide variety of pesticides from different compound classes.

Method development becomes more difficult if the analysis is extended to metabolites and other degradation products of pesticides. These compounds are often very polar. Thus even if the original pesticides can be analyzed by $G C$, the method often fails when applied to degradation products. Furthermore, the polar nature of most pesticides and their partial high water solubility explains why these compounds represent potential water pollutants. For such polar pesticides, liquid chromatographic methods can be applied successfully. Conventional detectors, such as UV or photodiode array detectors (DAD), can be used for an unambiguous identification of pesticides in environmental samples for certain compound classes, for example, nitrophenols [3]. Furthermore, $N$-methylcarbamates can be 
analyzed by means of a specific postcolumn reaction system using a fluorescence detector [4]. However, in most instances these detectors do not provide sufficient structural information for metabolism studies, nontarget analysis, or even target analysis in environmental samples because the UV spectra of a given pesticide compound class are often almost identical, and differences between compound classes are frequently small. Furthermore, several pesticides have a low UV absorbance because they lack a strong chromophore. Hence a UV or DAD detector is not universally applicable. However, combined liquid chromatography-mass spectrometry (LC-MS) has demonstrated its potential for analyzing a broad spectrum of pesticides, including both typical "GC pesticides" and "high-performance liquid chromatography pesticides" [5, 6].

Nowadays, thermospray (TSP) [5-15], particle-beam (PB) [16], and, more recently, electrospray (ESI) and atmospheric pressure chemical ionization (APCI) [17, 18] are the most commonly used LC-MS interfaces for target and nontarget analysis of pesticides from various matrices. At present, TSP is most widely used because of its sensitivity as compared to PB and its compatibility with conventional high-performance liquid chromatography (HPLC) systems as compared to ESI. The lack of structural information obtained from TSP mass spectra can readily be overcome, for example, by variation of the gas-phase and vaporizer temperature to induce controlled chemical reactions during TSP vaporization and ionization [7], the use of external ionization media and tandem mass spectrometry techniques [19], repeller-induced fragmentation [20], additional cluster ions formed with solvent or additive molecules, and by using the complementary information of positive and negative ion spectra $[7,14$, 15]. These techniques provide adequate structural information for the identification and confirmation of pesticides in environmental samples [6, 14].

In the present study, the mass spectrometric analysis of a series of $\mathrm{N}$-substituted amine and anilide, carbamate and thiocarbamate, phenylurea, phosphate, phosphonate, sulfonylurea and thiourea, and triazine and other $N$-heterocyclic pesticides is reported. HPLC in conjunction with thermospray ionization was used for monitoring environmental samples. One aim of the present study is to extend the multiresidue method we reported previously [6], where mainly full-scan experiments were performed. Therefore, additional pesticides were included and time-scheduled selected ion monitoring (SIM) experiments were performed.

Furthermore, a variety of methods are proposed that enhance the structural information from TSP spectra. Thus, the TSP spectra of sulfonylureas, anilides, and $N$-substituted amines show abundant fragmentation, which is formed either by thermal degradation of the neutral molecule followed by ionization or by decomposition of the quasimolecular ion. Comparison of the TSP spectra with ESI, fast-atom bombardment (FAB), and ${ }^{252} \mathrm{Cf}$ plasma desorption $\left({ }^{252} \mathrm{Cf}-\mathrm{PD}\right)$ spectra [and collision-activated dissociation (CAD) spectra of the quasimolecular ions] has been used for elucidating the degradation mechanism. The fragmentation level is lower with phenylureas, but a structural specific fragment also is observed that may be used to confirm a tentative identification based on the quasimolecular ion. APCI, ESI, and FAB spectra are again used to confirm the proposed pathways. Finally, for triazines and several $N$-heterocyclic compounds, which hardly show any fragmentation under TSP ionization, postcolumn addition of different alkylated amines to the carrier stream is applied to induce on-line derivatization reactions in the condensed phase of the vaporizer probe. Furthermore, by applying postcolumn on-line derivatization (POD), additional clustering and fragmentation reactions are observed for carbamates, phenylureas, and $N$-heterocyclic compounds in combination with solvent-mediated chemical ionization (CI).

\section{Experimental}

\section{Materials and Reagents}

The pesticide standards used in this work were purchased from Riedel-de Haen (Seelze-Hannover, Germany) and Promochem (Wesel, Germany) and ranged in purity from 97 to $99.5 \%$. Standards of the sulfonylurea herbicides were provided by E. I. du Pont de Nemours (Bad Homburg, Germany) and CibaGeigy (Frankfurt, Germany) except chlorosulfuron and metsulfuron-methyl (Riedel-de Haen), Methanol (HPLC grade, Riedel-de Haen) and purified water (Milli-Q water, Millipore, Bedford, MA) were used as solvents. Ammonium acetate was purchased from Aldrich (Steinheim, Germany), and polyethylene glycol 300 and 400, the alkylated amines, and caffeine were purchased from Fluka (Buchs, Switzerland).

\section{Sample Preparation}

The pesticides were extracted from water $(1 \mathrm{~L}, 10 \mathrm{~mL}$ min ${ }^{1}$ ) by using solid-phase extraction cartridges filled with 3-g C-18 material (Amchro, Sulzbach-Taunus, Germany). Four 2-mL methanol washes carried the pesticides trapped on the cartridge to a sample vial, Thereafter, the volume was reduced to $\approx 500 \mu \mathrm{L}$ by using a gentle stream of nitrogen. Finally, the internal standard (caffeine) was added and $50 \mu \mathrm{L}$ of the extract was injected into the LC-MS system. Alternatively, direct on-line enrichment with subsequent desorption to the analytical column was performed with a selfconstructed on-line extraction apparatus. In these experiments, $50-200 \mathrm{~mL}$ of the water sample were passed through a 10- $\times 2$-mm cartridge (Spark, The Netherlands) filled with $\sim 40-\mathrm{mg} \mathrm{C}-18$ material (Amchro). Desorption to the analytical column is achieved via 
elution with the initial gradient composition after column switching with a pneumatic six-port valve (Valco, Houston, TX).

\section{Liquid Chromatography}

Details of the experimental setup are described elsewhere [7]. Briefly, a postcolumn technique was employed to enhance sensitivity and selectivity. The liquid chromatography (LC) system consisted of a Varian (Palo Alto, CA) Model 5000 gradient liquid chromatograph and a Shimadzu (Kyoto, Japan) Model LC-9A pump for the postcolumn addition of reagent solution. Narrow bore 3-mm columns with a column flow rate of $0.6 \mathrm{~mL} \mathrm{~min} \mathrm{~m}^{-1}$ were used. An additional flow rate of $0.4 \mathrm{~mL} \mathrm{~min}^{-1}$ of a reagent solution was added postcolumn. The reagent solution consisted of $175-\mathrm{mM}$ aqueous ammonium acetate or, in some instances, additional reagent additives. LiChrocart cartridge columns $(125 \times 3 \mathrm{~mm}$ i.d.) packed with $5-\mu \mathrm{m}$ LiChrospher 60 RP-select B from Merck (Darmstadt, Germany) were used. Separation was accomplished by using the following eluent composition: methanol: water $=20: 80$ $(\mathrm{v} / \mathrm{v})$ was programed to $95: 5$ in $45 \mathrm{~min}$. The final composition was held for $15 \mathrm{~min}$. To keep the sulfonylureas, asulam, and bentazone in an undissociated form, they were separated with an acidified mobile phase. In this case, $100-\mathrm{mM}$ acetic acid was used instead of pure water. A 7125 injection valve (Rheodyne, Cotati, CA) equipped with a 20 - or $50-\mu \mathrm{L}$ loop was used to introduce the samples. To avoid peak broadening of early eluting compounds it is recommended that the sample solutions be injected with a high water content $(\geq 80 \%)$.

\section{Mass Spectrometry}

Many details of the TSP LC-MS configuration and operation have been reported earlier [6,7]. Briefly, a Finnigan-MAT 4500 mass spectrometer (FinniganMAT, San Jose, CA) was coupled with the LC system via a Vestec thermospray source (Houston, TX). The TSP temperatures were vaporizer control $T_{1} \approx 135-150$ ${ }^{\circ} \mathrm{C}$, vaporizer $T_{v} \approx 190-220{ }^{\circ} \mathrm{C}$, tip heater $T_{3}=270{ }^{\circ} \mathrm{C}$, source jet (vapor) $T_{g} \approx 230-240^{\circ} \mathrm{C}$, and source $T_{s}=250$ ${ }^{\circ} \mathrm{C}$. Discharge-assisted buffer ionization with ammonium acetate was used throughout all quantification experiments. The terms "thermospray ionization" and "solvent-mediated $\mathrm{Cl}^{\prime}$ " are used as described by Niessen and Van der Greef [21], that is, thermospray ionization refers to buffer ionization with a volatile salt and solvent-mediated $\mathrm{CI}$ refers to discharge ionization without buffer. In the present article both terms are also used to differentiate between the postcolumn ionization conditions obtained if either pure alkylated amines (solvent-mediated $\mathrm{CI}$ ) or their corresponding acetates (discharge-assisted buffer ionization) are added to the carrier stream. The discharge-assisted buffer ionization spectra are consistent with those obtained under normal TSP ionization, although in some cases a somewhat higher fragmentation is observed (see examples in the following text), whereas discharge-assisted buffer ionization and solvent-mediated CI often exhibit very different spectra [6].

Direct flow injection experiments were performed by using a final carrier stream of methanol : water $=$ $50: 50(\mathrm{v} / \mathrm{v})$ and postcolumn addition of $70-\mathrm{mM}$ ammonium acetate (the column and postcolumn flow rates are the same as those used for the HPLC separations). In several experiments, ammonium acetate is replaced by different organic modifiers that are added postcolumn and, again, with a concentration of $70 \mathrm{mM}$.

The lower limit of the mass spectrometer scan range depends on the solvent cluster ion spectrum and thus the organic modifier used. Usually, the mass spectrometry was either scanned at a rate of $1 \mathrm{~s}$ per scan over the range $m / z$ 120-450 (positive ions) and $m / z$ 185-500 (negative ions) or time-scheduled selected ion monitoring (SIM) was performed.

Low energy tandem mass spectrometry experiments were carried out on a Finnigan-MAT TSQ 70 triplestage quadrupole mass spectrometer (Q1, Q2, Q3) equipped with a Finnigan-MAT thermospray source. Collision-activated dissociation (CAD) was achieved within the rf-only quadrupole, where a collision offset (COFF) of $20 \mathrm{~V}$ was applied to $Q 2$. Argon was used as the collision gas with a collision cell pressure of $1.3 \times$ $10^{-3}$ torr. Direct flow injection was used to introduce the samples into the mass spectrometer. The carrier stream consisted of methanol: water - 50:50 (v/v) containing $50-\mathrm{mM}$ ammonium acetate. The aerosol temperature, $T_{g}^{\prime}$, was kept at $240^{\circ} \mathrm{C}$, while the vaporizer contrul temperature $T_{1}^{\prime}$ was varied between 70 and $95^{\circ} \mathrm{C}$.

Fast-atom bombardment (FAB) spectra were recorded on a Finnigan-MAT 8430 double-focusing mass spectrometer. 3-Nitrobenzyl alcohol (NBA) was used as the matrix in most instances. If the samples were not soluble in NBA or chemical reactions with NBA occurred, a glycerol matrix was used. Sample concentrations of $\sim 500 \mathrm{ng}$ per microliter of NBA were used. The samples were admitted by means of the standard direct-inlet probe carrying a stainless steel target. The scan speed was $3 \mathrm{~s}$ decade ${ }^{-1}$. Ions were produced by an $8-\mathrm{keV}$ primary beam of xenon atoms, extracted and accelerated with an $8-\mathrm{kV}$ potential. NBA exhibits intense matrix ions at $m / z 136,154$, $176,289,307$, and 329 .

${ }^{252} \mathrm{Cf}$ plasma desorption $\left({ }^{252} \mathrm{Cf}-\mathrm{PD}\right)$ mass spectra were recorded on a Bion-Ion Nordic AB (Uppsala, Sweden) plasma desorption time-of-flight (TOF) mass spectrometry system using a Mylar ${ }^{\oplus}$ (Alexander Vacuum Research, Boston, MA) film as target. Approximately $5 \mu \mathrm{L}$ of the sample solutions (concentration $\sim 300 \mathrm{ng} \mu \mathrm{L}^{-1}$ in methanol) were deposited on the Mylar foil. 
Electrospray and $\mathrm{APCI}$ experiments of phenylureas and sulfonylureas were performed on a Finnigan-MAT TSQ 700 mass spectrometer equipped with either an ESI or APCI source. With APCI, a vaporizer temperature of $400{ }^{\circ} \mathrm{C}$ was used. The samples were introduced into the ESI and APCI source with a carrier flow rate of $300 \mu \mathrm{L} \mathrm{min}^{-1}$ after separation on a minibore $125-\times 2$ mm (5- $\mu \mathrm{m})$ LiChrospher 100 RP-18 column (Merck). Solvents and gradient conditions were identical to those used in the TSP LC-MS investigation. Ammonium acetate was added to the carrier stream in some instances to enhance ionization (see text). The ESI spectra of the anilides were recorded on a triple-stage Perkin Elmer Sciex (Thornhill, Ontario, Canada) API III quadrupole mass spectrometer equipped with an electrospray source. Direct flow injection was used to introduce the samples into the carrier stream [methanol: water $=50: 50(\mathrm{v} / \mathrm{v})$; flow rate $50 \mu \mathrm{L}$ $\left.\min ^{-1}\right]$ in these samples.

\section{Results and Discussion}

A series of nitrogen- and phosphorus-containing pesticides was investigated by positive-ion thermospray LC-MS, as summarized in Table 1. The sulfonylureas and most of the phenylureas, the phosphonates, many carbamates, and certain amines cannot be analyzed by GC mass spectrometry because of their thermal instability and polarity. Therefore, these compounds were the preferred choice for LC-MS investigations. Other selected compounds lack a strong chromophore and thus cannot be detected at trace level with conventional LC UV detection. This is particularly the case for several amines and carbamates, for example, aldicarb, allidochlor, EPTC, mecarbam, methomyl, oxamyl, pebulate, propamocarb, thiofanox, thiodicarb, triallate, and vernolate, and the organophosphorous compounds investigated. Many typical "GC pesticides" are also amenable to TSP and HPLC. These compounds were also included to demonstrate the universality of the method.

\section{Evaluation of the Method}

We previously demonstrated the TSP LC-MS analysis of 95 pesticides using one common method with a single set of experimental parameters and full-scan mass spectrometry [6]. The former study showed that the reproducibility, linearity, and instrumental detection limits obtained were adequate for environmental monitoring of a broad spectrum of pesticides without necessitating the use of isotopically labeled internal standards.

Assuming a two-thousandfold concentration step via solid-phase extraction and an injection volume of $50 \mu \mathrm{L}$ into the LC system, a $\sim 5-10-n g$ amount has to be detected via TSP after LC separation to verify the
CEC drinking water level $\left(100 \mathrm{ng} \mathrm{L}^{-1}\right)$. However, for several pesticides this criterion could not be achieved with full-scan analysis. In the present study the experiments were extended to time-scheduled SIM measurements to lower the detection limit of the method to the low parts-per-trillion range. In addition, new compounds are included in the list, for example, sulfonylureas and several thiocarbamates.

A typical TSP full-scan chromatogram of a standard solution of 27 carbamates and thiocarbamates is shown in Figure 1 (injected amount, $\sim 180 \mathrm{ng}$ each). During all chromatographic experiments, caffeine was added as an internal standard.

A list of the retention times of 50 important pesticides is presented in Table 2 together with their ammonium acetate TSP quantitation ions, second most abundant fragment or cluster ions, and detection limits (LOD) obtained by time-scheduled SIM. Verification of the CEC limit concentration is quite possible for all investigated compounds under these conditions. Most of the pesticides can be detected down to the lower picogram range per compound injected into the column. This is demonstrated in Figure 2, where the time-scheduled SIM trace for the injection of $100 \mathrm{pg}$ of four phenylureas is shown (Table 2 lists the corresponding quantitation ions). Similar detection limits also are observed for triazines and many carbamates.

In general, although sensitivities varied widely from compound to compound (Table 2), positive-ion TSP analysis was more sensitive than negative-ion analysis, the results of which are not shown in this report. However, in some instances the combination of both ionization modes provides valuable additional structural information for the characterization of pesticides as previously reported for carbamates [7].

\section{Analysis of a River Water Extract}

In this section, an example for the parts-per-trillion level determination and confirmation of several phenylureas from a spiked river water sample is shown. The unambiguous identification of phenylureas is more difficult than that of many other pesticides because they lack intense fragment ions in the "usual" TSP scan range of $m / z 120-450$. However, in the case of $N, N$-dimethylureas, such confirmation is possible by using the abundant fragment ion at $m / z 46$ to confirm the identification based on the quasimolecular ion (the origin of this ion is described in more detail below). This is demonstrated in Figure 3, where the results of two TSP LC-MS separations of an extract of a water sample (river water) are shown. The original water sample was spiked with nine phenylureas at a concentration of $100 \mathrm{ng} \mathrm{L}^{-1}$ (CEC limit). Preconcentration was achieved via solid-phase extraction. Fifty microliters of the methanol extract were injected. The separation and mass spectrometry detection were per- 
Table 1. Pesticides and some of their transformation products investigated in this study

\begin{tabular}{|c|c|}
\hline Anilides and $N$-substituted amines & Carbamates and thiocarbamates \\
\hline Alachlor & Aldicarb \\
\hline Allidochlor & Aldicarb sulfone \\
\hline Bentazone & Aldicarb sulfoxide \\
\hline Butachlor & Asulam \\
\hline Carboxin & Barban \\
\hline Dimethachlor & Benomyl \\
\hline Oxicarboxin & Carbaryl \\
\hline Metalaxyl & Carbetamide \\
\hline Metazachior & Carbofuran \\
\hline Methfuroxam & Chlorpropham \\
\hline Metolachlor & Desmedipham \\
\hline Monalide & EPTC \\
\hline Pendimetalin & Mecarbam \\
\hline Pentanochlor & Methiocarb \\
\hline Prochloraz & Methomyl \\
\hline Propachlor & Oxamyl \\
\hline Propanil & Pebulate \\
\hline Tebutam & Phenmedipham \\
\hline Trifluralin & Pirimicarb \\
\hline & Promecarb \\
\hline Phenylureas and thioureas & Propham \\
\hline Chlorbromuron & Propoxur \\
\hline Chlorotoluron & Prosulfocarb \\
\hline Chloroxuron & Pyridate \\
\hline Difenoxuron & SWEP \\
\hline Diuron & Thiodicarb \\
\hline Fenuron & Thiofanox \\
\hline Fluometuron & Triallate \\
\hline Isocarbamide & Vernolate \\
\hline \multicolumn{2}{|l|}{ Isoproturon } \\
\hline Linuron & Sulfonylureas \\
\hline Metabenzthiazuron & Bensulfuron-methyl \\
\hline Metobromuron & Chlorimuron-methyl \\
\hline Metoxuron & Chlorsulfuron \\
\hline Monolinuron & Metsulfuron-methyl \\
\hline Monuron & Primisulfuron-methyl \\
\hline & Sulfometuron \\
\hline \multirow{2}{*}{$\begin{array}{l}\text { Triazines and } N \text {-heteracyclic compounds } \\
\text { Ametryn }\end{array}$} & Thifensulfuron-methyl \\
\hline & Tribenuron-methyl \\
\hline \multicolumn{2}{|l|}{ Anilazine } \\
\hline Atratone & Organophosphorous compounds \\
\hline Cyanazine & Butonate \\
\hline Desmetryn & Dichlorovos \\
\hline Metribuzine & Trichlorfon \\
\hline \multicolumn{2}{|l|}{ Prometryn } \\
\hline \multicolumn{2}{|l|}{ Propazine } \\
\hline \multicolumn{2}{|l|}{ Secbumetone } \\
\hline \multicolumn{2}{|l|}{ Sebutylazine } \\
\hline \multicolumn{2}{|l|}{ Simazine } \\
\hline \multicolumn{2}{|l|}{ Terbutylazine } \\
\hline Terbutryn & \\
\hline
\end{tabular}

formed with time-scheduled SMM of the $[\mathrm{MH}]^{+}$ions and the ion at $m / z 46$. Identification and confirmation of the $N, N$-dimethyl-phenylureas are quite possible even at this low concentration. [The time window for difenoxuron (peak 8) at $m / z 287$ is not applied in the time-scheduled SIM analysis (Figure 3a) because the retention time is very similar to peak 7. However,
Figure $3 b$ indicates the presence of difenoxuron.] Slight differences in retention times between Figure $3 a$ and $b$ are due to the separate chromatographic analyses. Therefore, in critical cases both ions should be included in one time window during time-scheduled SIM.

Figure 3 and Table 2 clearly demonstrate that iden- 


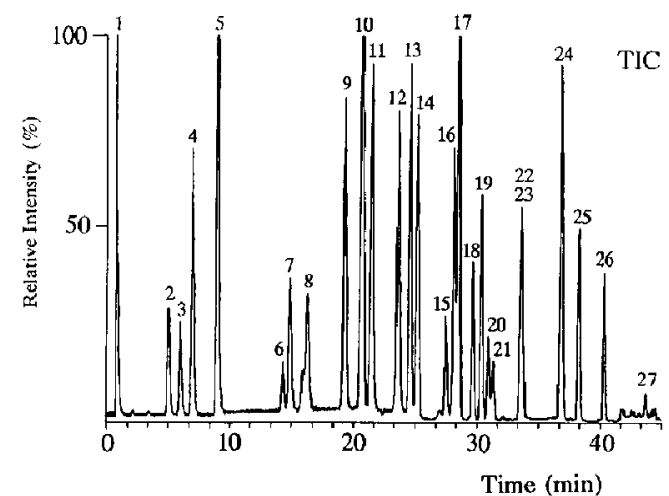

Figure 1. Discharge-assisted TSP chromatogram of 27 carbamates and thiocarbamates and some of their degradation products under full-scan conditions (injected amount: $180 \mathrm{ng}$ each). Experimental conditions: $T_{g} \approx 235^{\circ} \mathrm{C}, T_{v}=220 \rightarrow 209^{\circ} \mathrm{C}$. For details, see Experimental section. Peak assignments: 1, asulam; 2 aldicarb sulfone; 3 , methomyl; 4 , oxamyl; 5 , caffeine (internal standard); 6, 3-methoxy-carbonyl-aminophenylalcohol; 7, benomyl; 8, aldicarb; 9, carbetamide; 10, propoxur; 11 , carbofuran; 12 , carbaryl; 13, pirimicarb; 14, propham; 15, thiodicarb; 16 , desmedipham; 17, phenmedipham; 18, chlorpropham; 19, promecarb; 20, methiocarb; 21, barban; 22, SWEP; 23, EPTC; 24, pebulate/vernolate; 25 , prosulfocarb; 26 , triallate; 27 , pyridate.

tification, quantification, and confirmation are quite possible in this low concentration range for almost all of the investigated pesticides.

\section{Enhancing Structural Information from}

Thermospray Spectra and Confirmation of

Pesticide Residues. Application of Other Ionization Techniques

Triazines and other N-heterocyclic compounds. Thermospray and solvent-mediated CI spectra of triazines, pyrimidines, triazoles, and many other compounds that contain an $N$-heterocyclic moiety are usually very simple and consist in general only of $[\mathrm{MH}]^{+}$ions because of their high proton affinity in comparison to ammonia, methanol, or water. The lack of structurally significant fragments limits the specificity of analysis. Voyskner [11] demonstrated the usefulness of tandem mass spectrometry techniques in the analysis of chlorotriazines to overcome this problem. In this study we report an alternative approach to enhance structural information from chlorotriazine spectra by using postcolumn on-line derivatization (POD) reactions in the condensed phase of the vaporizer probe. These derivatizations are performed in combination with solventmediated chemical ionization via discharge ionization or normal TSP ionization. POD leads on the one hand to a chlorine substitution by the amine, and on the other hand to adduct ion formation. Both processes are useful to enhance structural information from TSP spectra and thus the selectivity of the method.
POSTCOLUMN DERIVATIZATION OF CHLOROTRIAZINES WITH ALIPHATIC AMINES. The TSP spectra of monochlorotriazines exhibit unusual $[M-5]^{+}$and $[M+9]^{*}$ ions with no chlorine isotope pattern when methylamine and dimethylamine, respectively, are added postcolumn to the carrier stream instead of the usual ammonium acetate. Figures 4 and 5 demonstrate the influence of different additives on the ion abundance of atrazine and anilazine (see also Experimental section). Other chlorotriazines, such as cyanazine, propazine, sebutylazine, simazine, and terbutylazine, behave similarly. Table 3 summarizes these results for the chlorotriazines investigated as well as further results obtained with structurally different triazines.

Obviously, a nucleophilic substitution of the chlorine atom takes place as is typical for $\pi$-deficient heteroaromatics. These substitutions most probably occur as condensed-phase reactions in the vaporizer probe prior to ionization and most likely are assisted by heat and solvent, that is, the TSP interface is used as a flow reactor for the derivatization reactions. Structurally specific ions, viz. $\left[\mathrm{M}-\mathrm{Cl}+\mathrm{HNCH}_{3}+\mathrm{H}\right]^{+}(=[\mathrm{M}-$ $\left.5]^{+}\right)$and $\left[\mathrm{M}-\mathrm{Cl}+\mathrm{N}\left(\mathrm{CH}_{3}\right)_{2}+\mathrm{H}\right]^{+}\left(=[\mathrm{M}+9]^{+}\right)$, are observed. The extent of substitution depends on the structure of the triazine and the nucleophilicity of the amine. Therefore, by adding dimethylamine, higher reaction yields are obtained (Table 3 ) and a complete substitution usually occurs. POD reactions are observed in both the TSP and the solvent-mediated CI mode with an identical extent of substitution. In the discharge mode, additional $[\mathrm{MH}-34]^{+}$and $\left[\mathrm{M}_{s} \mathrm{H}-\right.$ $34]^{+}$ions, respectively, are observed that result from a loss of a chlorine atom, where $M_{s}$ is the protonated POD product ion. These $[\mathrm{M}-\mathrm{Cl}+2 \mathrm{H}]^{+}$and $\left[\mathrm{M}_{s}-\right.$ $\mathrm{Cl}+2 \mathrm{H}]^{+}$ions are formed by substitution of a chlorine atom by a hydrogen atom. This fragmentation is discussed in more detail below.

If an equimolar amount of acetic acid is added to the postcolumn amine solution (discharge-assisted buffer ionization) the signal for $\left[\mathrm{M}-\mathrm{Cl}+\mathrm{HNCH}_{3}+\right.$ $\mathrm{H}^{+}$and $\left[\mathrm{M}-\mathrm{Cl}+\mathrm{N}\left(\mathrm{CH}_{3}\right)_{2}+\mathrm{H}\right]^{+}$almost disappears (Figure $4 \mathrm{a}$ and b). This behavior is consistent with the proposed nucleophilic substitution because methylammunium acetate and dimethylammonium acetate do not exhibit nucleophilicity.

The spectrum of anilazine shows POD product ions that are due to the substitution of both chlorines bound to the heterocyclic aromatic ring. As expected, the phenyl-bound chlorine is not substituted by the nucleophilic reagents. (Loss of this chlorine atom may be observed under certain experimental conditions. This loss is due to a radical reductive dechlorination prior to ionization. However, this reaction occurs with all reagent additives and is only induced by the CI plasma. For details, see below.) The signal at $m / z 256$ in the spectrum of anilazine (Figure 5a) with ammonium acetate as the additive apparently corresponds to a POD product obtained by chlorine-ammonia substitution. 
Table 2. Elution order, main positive ions, and SIM detection limits (LOD) in the TSP LC-MS analysis of important pesticides and some of their transformation products

\begin{tabular}{|c|c|c|c|c|c|c|}
\hline No. & $\begin{array}{l}\text { Compound } \\
\text { Common name }\end{array}$ & $M_{n}^{\mathrm{a}}$ & $\begin{array}{l}\text { Retention time } \\
\text { (min) }\end{array}$ & $\begin{array}{l}\text { Quantitation } \\
\text { ion }\end{array}$ & $\begin{array}{l}\text { Second } \\
\text { ion }^{b}\end{array}$ & $\begin{array}{l}\text { LOD } \\
(\mathrm{pg})^{\circ}\end{array}$ \\
\hline 1 & Aldicarb sulfoxide & 206 & 4.10 & 224 & $207(65)$ & 500 \\
\hline 2 & Aldicarb sulfone & 222 & 4.27 & 240 & $165(70)$ & 600 \\
\hline 3 & Oxamyl & 219 & 5.48 & 237 & $163(20)$ & 300 \\
\hline 4 & Methomyl & 162 & 6.68 & 163 & $180(10)$ & 200 \\
\hline 5 & Caffeine $^{\alpha}$ & 194 & 8.50 & 195 & - & 70 \\
\hline 6 & Fenuron & 164 & 10.77 & 165 & $182(40)$ & 50 \\
\hline 7 & Isocarbamide & 185 & 15.00 & 186 & $146(5)$ & 100 \\
\hline 8 & Benomyl & 290 & 15.05 & 192 & $134(90)$ & 300 \\
\hline 9 & Allidochlor & 173 & 15.97 & 174 & $191(15)$ & 50 \\
\hline 10 & Aldicarb & 190 & 16.27 & 208 & $191(30)$ & 200 \\
\hline 11 & Metoxuron & 228 & 17.47 & 229 & $201(8)$ & 300 \\
\hline 12 & Monuron & 198 & 20.05 & 199 & $171(5)$ & 100 \\
\hline 13 & Propoxur & 209 & 20.77 & 227 & $210(20)$ & 100 \\
\hline 14 & Carbofuran & 221 & 21.57 & 222 & $239(35)$ & 70 \\
\hline 15 & Carbaryl & 201 & 23.72 & 219 & $202(18)$ & 80 \\
\hline 16 & Monolinuron & 214 & 23.85 & 215 & $232(10)$ & 60 \\
\hline 17 & Pirimicarb & 251 & 24.58 & 252 & - & 40 \\
\hline 18 & Chlorotoluron & 212 & 24.92 & 213 & $185(5)$ & 40 \\
\hline 19 & Metobromuron & 258 & 25.11 & 259 & $276(10)$ & 200 \\
\hline 20 & Propham & 179 & 25.42 & 197 & $180(90)$ & 60 \\
\hline 21 & Metabenzthiazuron & 221 & 25.98 & 222 & $165(17)$ & 200 \\
\hline 22 & Metazachlor & 277 & 26.03 & 278 & $244(8)$ & 100 \\
\hline 23 & Isoproturon & 206 & 26.28 & 207 & $179(12)$ & 100 \\
\hline 24 & Propachlor & 211 & 26.30 & 212 & $229(10)$ & 200 \\
\hline 25 & Metalaxyl & 279 & 26.52 & 280 & - & 300 \\
\hline 26 & Atrazine & 215 & 26.73 & 216 & $182(10)$ & 90 \\
\hline 27 & Dimethachlor & 255 & 27.00 & 256 & $222(38)$ & 300 \\
\hline 28 & Diuron & 232 & 27.08 & 233 & $250(10)$ & 100 \\
\hline 29 & Methfuroxam & 229 & 27.52 & 230 & - & 200 \\
\hline 30 & Difenoxuron & 286 & 27.65 & 287 & $216(68)$ & 100 \\
\hline 31 & Desmedipham & 300 & 28.38 & 199 & $137(60)$ & 100 \\
\hline 32 & Phenmedipham & 300 & 28.61 & 185 & $168(45)$ & 90 \\
\hline 33 & Carbetamide & 236 & 28.73 & 237 & $177(28)$ & 200 \\
\hline 34 & Linuron & 248 & 29.92 & 249 & $266(18)$ & 70 \\
\hline 35 & Chlorpropham & 213 & 30.00 & 231 & $214(30)$ & 200 \\
\hline 36 & Terbutylazine & 229 & 30.30 & 230 & $196(10)$ & 100 \\
\hline 37 & Propanil & 217 & 30.80 & 218 & $235(65)$ & 300 \\
\hline 38 & Methiocarb & 225 & 31.38 & 243 & $226(65)$ & 100 \\
\hline 39 & Barban & 257 & 31.78 & 275 & $258(10)$ & 300 \\
\hline 40 & Mecarbam & 329 & 32.01 & 330 & $347(20)$ & 200 \\
\hline 41 & Chloroxuron & 290 & 32.18 & 291 & $220(20)$ & 90 \\
\hline 42 & Alactilor & 269 & 32.93 & 270 & $226(88)$ & 400 \\
\hline 43 & Metolachlor & 283 & 33.40 & 284 & $250(33)$ & 200 \\
\hline 44 & Monalide & 239 & 34.17 & 240 & - & 200 \\
\hline 45 & Pentanochlor & 239 & 35.63 & 240 & $257(5)$ & 200 \\
\hline 46 & Pendimetalin & 281 & 35.88 & 282 & $220(50)$ & 300 \\
\hline 47 & Prochloraz & 375 & 36.25 & 376 & $180(90)$ & 200 \\
\hline 48 & Trifluralin & 335 & 36.55 & 276 & $336(80)$ & 300 \\
\hline 49 & Prosulfocarb & 251 & 38.80 & 239 & - & 100 \\
\hline 50 & Triallate & 303 & 40.93 & 304 & $162(20)$ & 100 \\
\hline 51 & Butachlor & 311 & 41.10 & 226 & $238(95)$ & 300 \\
\hline
\end{tabular}

${ }^{a} M_{n}=$ nominal mass.

b This column lists the most abundant structurally significant fragment ion or molecule cluster ion, although in some instances isotopic peaks of the quantitation ion are more abundant. The abundance in parentheses is listed relative to the quantitation ion (base peak).

cSignal-to-noise ratio $=3$. The values are cited to one significant figure.

dinternal standard. 


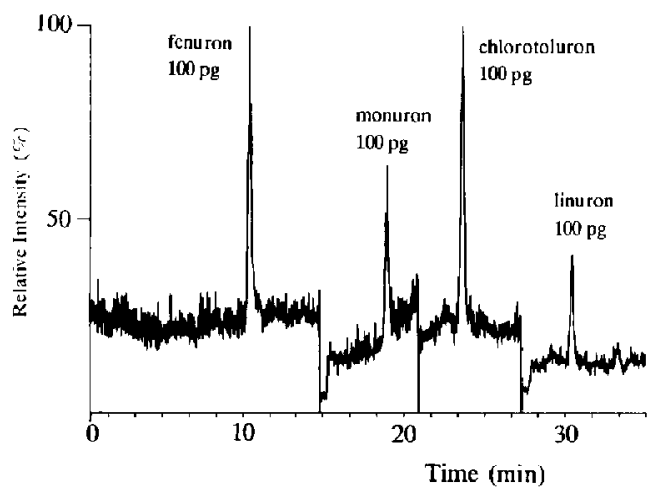

Figure 2. Discharge-assisted TSP LC-MS analysis of pheny]ureas: time-scheduled SIM trace for the injection of $100 \mathrm{pg}$ of each compound.
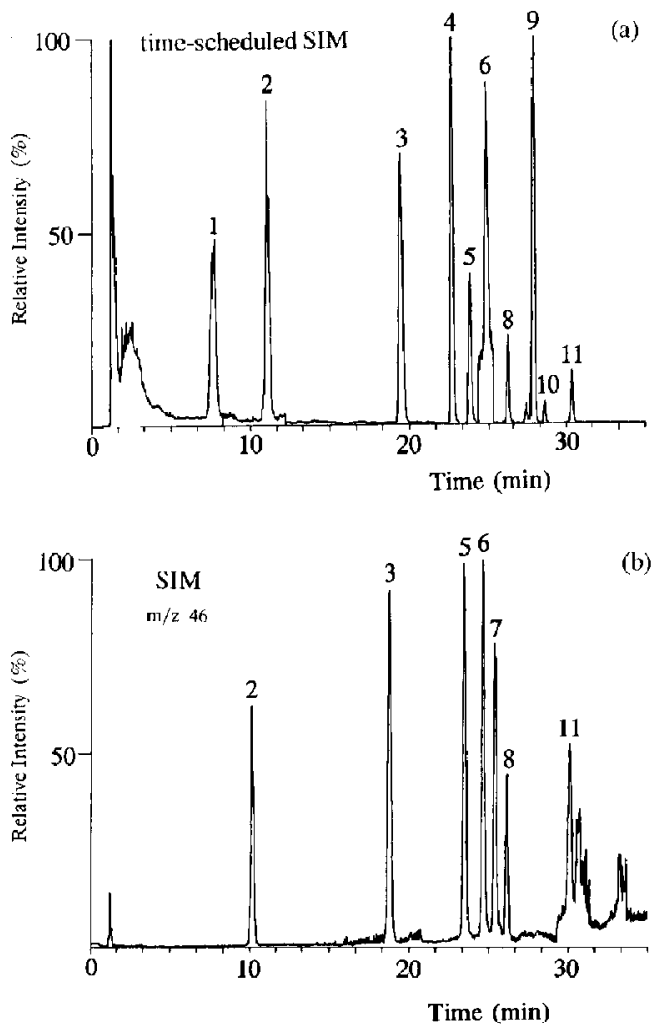

Figure 3. Analysis of a river water extract (River Leine, Hannover) by TSP LC-MS. The original water sample was spiked with phenylureas at the $100 \mathrm{ng} \mathrm{L}^{-1}$ level. Peak assignments: 1 , caffeine; 2, fenuron; 3, monuron; 4, linuron; 5, chlorotoluron; 6 , isoproturon; 7 diuron; 8 , difenoxuron; 9 , linuron; 10 , chlorbromuron; 11, chloroxuron. (a) Time-scheduled SIM ISP chromatogram of the $[\mathrm{MH}]^{+}$ions; (b) confirmation of $N, N$ dimethyl-phenylureas. The SIM trace of protonated dimethylamine is formed from dissociation of the phenylurea to its $\left[\mathrm{MH}-\right.$ PheNCO] $^{+}$ion $(m / z 46)$.
The mechanism for the chlorine-hydrogen substitution in the POD spectrum of atrazine obtained with trimethylammonium acetate that leads to the ion at $\mathrm{m} / \mathrm{z} 182$ is not yet clear (Figure 4c). Furthermore, the sensitivity obtained with this reagent is not satisfactory for analytical purposes (Table 4).

As expected, alkylthiotriazines and alkoxytriazines do not undergo nucleophilic substitution, as can be seen from Table 3 .

Although the reactions described strongly depend on the interface temperatures and therefore careful adjustment of the temperatures is necessary for reproducible results, the reactions can be induced over the entire operating range of the TSP interface, viz. $T_{v} \approx$ $160-230^{\circ} \mathrm{C}$ and $T_{\mathrm{g}} \approx 190-290{ }^{\circ} \mathrm{C}$. However, isobaric and isomeric compounds, for example, propazine and terbutylazine could not be distinguished from their POD spectra. That is, tandem mass spectrometry should be applied in these cases [11].

CLUSTER ION FORMATION. In sOme instances, alkylammonium cluster ions of triazines are observed, especially if trimethylamine is added (Figure 4 and Table 3 ). This is due to the higher proton affinity of the alkylamines, PA(B), as compared to ammonia. Hence protonation of the triazines is less exothermic and attachment of the ionizing cluster ions becomes more favored. We have investigated the effect of the proton affinity on the ion abundance of scveral compounds in the range $\mathrm{PA}(\mathrm{B})=853-942 \mathrm{~kJ} \mathrm{~mol}^{-1}$ by applying postcolumn addition of various alkylated amines. The reagents used are summarized in Table 4. All proton affinities are from Lias and co-workers $[22,23]$.

The TSP reagent ion spectra of the postcolumn mixtures under thermospray and discharge ionization are very simple and usually consist of only [amine $\cdot \mathrm{H}]^{+}$, [amine $\cdot \mathrm{CH}_{3} \mathrm{OH} \cdot \mathrm{H}^{+}$, and $\left[(\text {amine })_{2} \cdot \mathrm{H}\right]^{+}$ions if pure amine is added, whereas the spectra of the corresponding acetates contain additional ions, which are due to clusters of these ions with acetic acid, $\mathrm{N}$ alkylacetamide, water, and methanol and mixtures of these ions, respectively.

The spectra of several $N$-heterocyclic compounds undergo a "transition" from the [MH]' ion to the $[\mathrm{M} \cdot \mathrm{H} \cdot \text { amine }]^{+}$ion, if the PA is changed (the PA of these compounds are within the investigated range of PA(B) $=853-942 \mathrm{~kJ} \mathrm{~mol}^{-1}$ ). As an example, the effect of the proton affinity on the spectra of the triazinone pesticide metribuzine is summarized in Figure 6, where the ratio of the ion current of the $[\mathrm{MH}]^{+}$ion relative to the adduct ion $\left[\mathrm{M} \cdot \mathrm{H} \cdot\right.$ amine $^{+}, r(\mathrm{M})$, is plotted against PA ( $r(\mathrm{M})$ is defined as described in [7]). A strong shift to the $[\mathrm{MH}]^{+}$ion is observed with decreasing PA. Ionizing with ammonia usually leads to the regular TSP spectra of $\mathrm{N}$-heterocyclic compounds, that is, only the $[\mathrm{MH}]^{+}$ion is formed. The correlation is valid for both the pure alkylated amine and the alkylammonium acetate, that is, identical spectra are observed. 
(a)

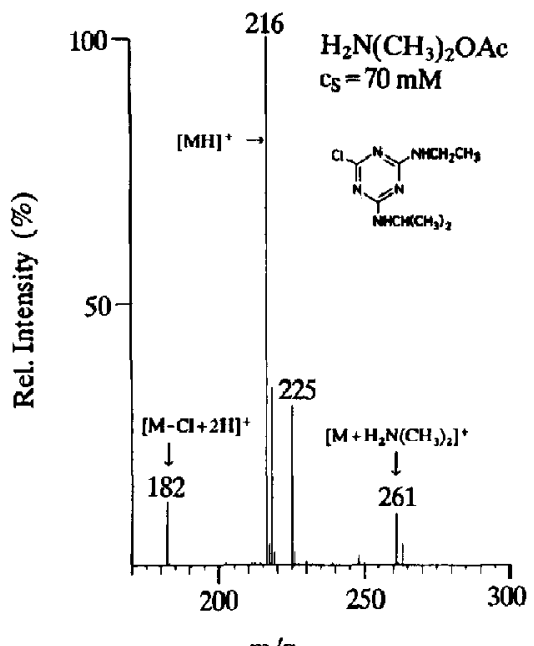

(b)

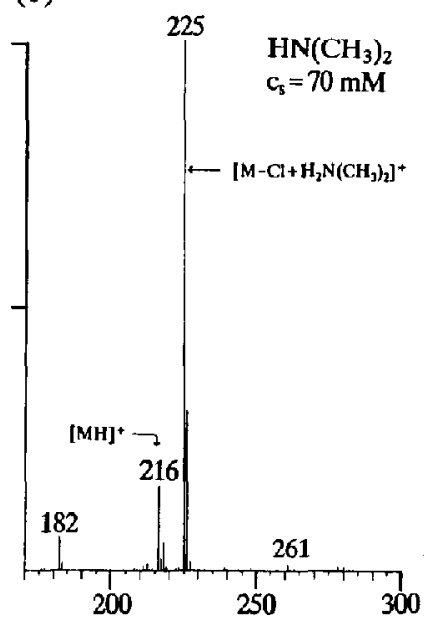

$\mathrm{m} / \mathbf{z} \longrightarrow$ (c)

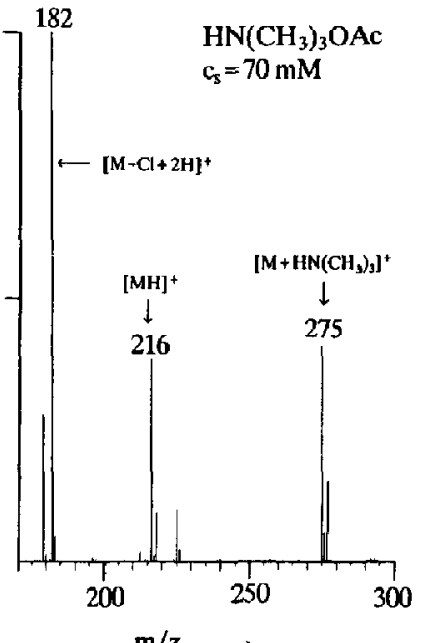

Figure 4. Thermospray postcolumn on-line derivatization (POD). Variation of ion abundances in TSP mass spectra with condensed-phase nucleophilicities and gas-phase proton affinities. POD spectra of atrazine: postcolumn addition of (a) dimethylammonium acetate (discharge-assisted TSP), (b) dimethylamine (solvent-mediated $\mathrm{CI}$ ), and (c) trimethylammonium acetate (discharge-assisted TSP).

These cluster ions may be of value in TSP SIM analysis of environmental samples, for example. In some instances, we observed a very noisy baseline for some ions during SIM experiments with ammonium acetate. Although the absolute ion itensities are not affected, the signal-to-noise ratios are unsatisfactory in such instances. This behavior is due to either an interfering solvent cluster ion of high mass or, more probably, to a contamination of the source after repetitive injection of sample extracts. In such instances it is very useful to switch to an alternative ion of equal or comparable intensity for quantitation. This is especially important for pesticides with proton affinities in the range of ammonia, that is, for most carbamates, phenylureas, anilides, and organophosphorous compounds. These compounds form almost exclusively $[\mathrm{M} \cdot \mathrm{H} \cdot \text { amine }]^{+}$ions by ionization with protonated alkylated amines. Therefore, it is important to compare (a)

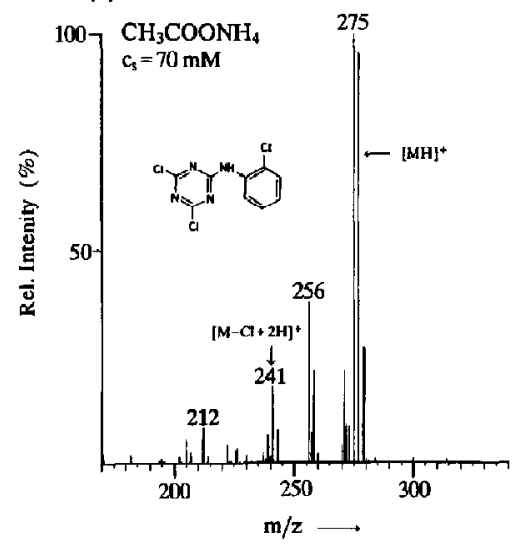

(b)

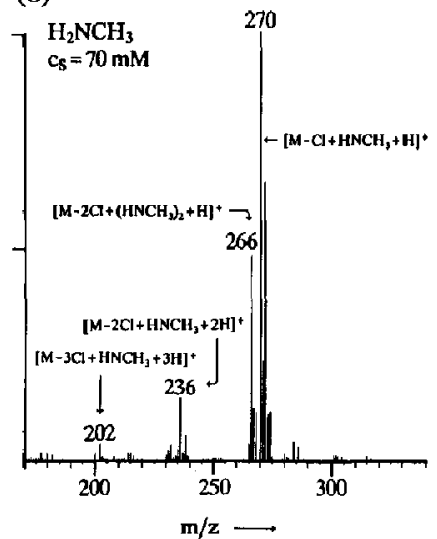

(c)

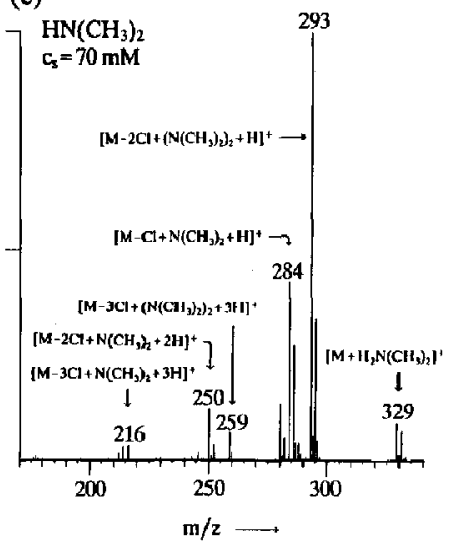

Figure 5. TSP POD spectra of anilazine: postcolumn addition of (a) ammonium acetate (dischargeassisted buffer ionization), (b) methylamine (solvent-mediated $\mathrm{CI}$ ), and (c) dimethylamine (solventmediated CI). 
Table 3. Summary of POD mass spectral data obtained from the solvent-mediated $\mathrm{CI}$ (discharge) analysis of triazines after postcolumn addition of methylamine and dimethylamine ${ }^{\mathrm{a}}$

\begin{tabular}{|c|c|c|c|c|c|c|c|c|}
\hline \multirow[b]{2}{*}{ Compound } & \multirow[b]{2}{*}{$M_{n}$} & \multirow[b]{2}{*}[\mathrm{MH}]{$^{+b}$} & \multicolumn{3}{|c|}{$\mathrm{CH}_{3} \mathrm{NH}_{2}$} & \multicolumn{3}{|c|}{$\left(\mathrm{CH}_{3}\right)_{2} \mathrm{NH}$} \\
\hline & & & {$\left[\mathrm{M}_{s} \mathrm{H}\right]^{+\mathrm{c}}$} & $\gamma(\%)^{\mathrm{d}}$ & Adduct $^{e}$ & {$\left[\mathrm{M}_{s} \mathrm{H}\right]^{+}$} & $\gamma(\%)$ & Adduct \\
\hline \multicolumn{9}{|l|}{$\overline{\text { Chlorotriazines }}$} \\
\hline Anilazine $^{\dagger}$ & 274 & 275 & $266 / 70$ & 100 & - & $284 / 93$ & 100 & $329(15)$ \\
\hline Atrazine & 215 & 216 & 211 & 3 & - & 225 & 76 & $261(3)$ \\
\hline Cyanazine & 240 & 241 & 236 & 5 & $272(35)$ & 250 & 45 & $286(25)$ \\
\hline Propazine & 229 & 230 & 225 & 5 & - & 239 & 82 & $273(3)$ \\
\hline Sebutylazine & 229 & 230 & 225 & 2 & - & 239 & 27 & $275(4)$ \\
\hline Simazine & 201 & 202 & 197 & 12 & - & 211 & 97 & - \\
\hline Terbutylazine & 229 & 230 & 225 & 5 & - & 239 & 85 & $275(1)$ \\
\hline \multicolumn{9}{|l|}{ Alkylthiotriazines } \\
\hline Ametryn & 227 & 228 & - & 0 & - & - & 0 & - \\
\hline Desmetryn & 213 & 214 & - & 0 & - & - & 0 & - \\
\hline Prometryn & 241 & 242 & - & 0 & - & - & 0 & - \\
\hline Terbutryn & 241 & 242 & - & 0 & - & - & 0 & - \\
\hline \multicolumn{9}{|l|}{ Alkoxytriazines } \\
\hline Atratone & 211 & 212 & - & 0 & - & - & 0 & - \\
\hline Secbumetone & 225 & 226 & - & 0 & - & - & 0 & - \\
\hline
\end{tabular}

${ }^{\text {a }}$ For experimental conditions, refer to Table 4.

Mass-to-charge ratio of the protonated precursor compound.

Mass-to-charge ratio of the protonated substitution product: $\left[\mathrm{M}_{s} \mathrm{H}\right]^{+}=\left[\mathrm{M}-\mathrm{Cl}+\mathrm{NHCH}_{3}+\mathrm{HI}^{+}\right.$(methylamine); $\left[\mathrm{M}{ }_{s} \mathrm{H}\right]^{+}=[\mathrm{M}-\mathrm{Cl}+$ $\left.\mathrm{N}\left(\mathrm{CH}_{3}\right)_{2}+\mathrm{H}\right]^{\prime}$ (dimethylamine). Note that in the discharge-assisted TSP spectra that use $\mathrm{CH}_{3} \mathrm{CO}_{2} \mathrm{NH}_{4}$ the $[\mathrm{MH}]^{+}$ion is always the base peak and no other ions except the $[\mathrm{M}-\mathrm{Cl}+2 \mathrm{H}]^{+}$are present.

${ }^{d}$ Substitution is defined in terms of relative abundances: $\gamma=\sum\left(\left[\mathrm{M}_{s} \mathrm{H}\right]^{+}+\left[\mathrm{M}_{s}-\mathrm{Cl}+2 \mathrm{H}\right]^{+}\right) /\left([\mathrm{MH}]^{+}+\left[\mathrm{M}_{s} \mathrm{H}\right]^{+}+[\mathrm{M} s-\mathrm{Cl}+2 \mathrm{H}]^{+}+[\mathrm{M} \cdot \mathrm{H}\right.$. amine $\left.]^{+}\right) \times 100$ (it is assumed that the ionization efficiency is approximately the same for $M$ and $M_{s}$ ). Values represent the means of at least three determinations.

$[\mathrm{M} \cdot \mathrm{H} \cdot \text { amine }]^{+}\left(\%\right.$ abundance relative to the base peak $[\mathrm{MH}]^{+}$or $\left[\mathrm{M}_{s} \mathrm{H}\right]^{+}$). Anilazine exhibits $\left[\mathrm{M}_{s} \cdot \mathrm{H} \cdot \text { amine }\right]^{+}$ions.

Substitution of two chlarine atoms.

the sensitivities obtained by adding different postcolumn mixtures with that obtained with ammonium acetate. Table 4 summarizes these results for the different ionization modes applied to the carbamate pirimicarb, which contains an $\mathrm{N}$-heterocyclic moiety. Observe that only amines of lower molecular weight give satisfying results, which are comparable to ammonium acetate. In addition, solvent-mediated CI yields higher sensitivities than discharge-assisted buffer ionization. The relative sensitivities shown in Table 4 are typical for all investigated compounds.

Similar considerations hold for POD reactions, that is, only methylamine and dimethylamine should be used in analytical applications. Ionizing with a mixture of methylamine or dimethylamine and ammonium acetate is not advantageous: although the sensitivity is

Table 4. Comparison of TSP, discharge-assisted buffer ionization, and solvent-mediated CI sensitivities for pirimicarb obtained by postcolumn addition of several alkylated amines and their acetates ${ }^{\mathrm{a}}$

\begin{tabular}{|c|c|c|c|c|c|c|}
\hline \multirow[b]{2}{*}{ Amine $^{b}$} & \multirow[b]{2}{*}{$M_{n}$} & \multirow[b]{2}{*}{$\mathrm{PA}^{\mathrm{c}}$} & \multicolumn{2}{|c|}{$\mathrm{R}_{3} \mathrm{~N}$} & \multicolumn{2}{|c|}{$\mathrm{R}_{3} \mathrm{~N} \cdot \mathrm{H} \cdot \mathrm{OAc}$} \\
\hline & & & $\overline{\mathrm{SMC}} \mathrm{I}^{\mathrm{d}}$ & TSP & DATSP $^{\mathrm{e}}$ & TSP \\
\hline $\mathrm{NH}_{3}$ & 17 & 853 & - & - & 100 & 30 \\
\hline $\mathrm{CH}_{3} \mathrm{NH}_{2}$ & 31 & 896 & 95 & 12 & 61 & 6 \\
\hline$\left(\mathrm{CH}_{3}\right)_{2} \mathrm{NH}$ & 45 & 923 & 87 & 9 & 50 & 9 \\
\hline$\left(\mathrm{CH}_{3}\right)_{3} \mathrm{~N}$ & 59 & 942 & 38 & 4 & 35 & $<1$ \\
\hline $\mathrm{C}_{2} \mathrm{H}_{5} \mathrm{NH}_{2}$ & 45 & 908 & 79 & 3 & 66 & 10 \\
\hline$i-\mathrm{C}_{3} \mathrm{H}_{7} \mathrm{NH}_{2}$ & 59 & 915 & 60 & 6 & 43 & 7 \\
\hline$t-\mathrm{C}_{\mathbf{4}} \mathrm{H}_{\mathbf{g}} \mathrm{NH}_{2}$ & 73 & 924 & 30 & 5 & 20 & 5 \\
\hline$n-\mathrm{C}_{5} \mathrm{H}_{11} \mathrm{NH}_{2}$ & 87 & 916 & 21 & 5 & 20 & 5 \\
\hline$n-\mathrm{C}_{6} \mathrm{H}_{13} \mathrm{NH}_{2}$ & 101 & 920 & 14 & 5 & 12 & 3 \\
\hline
\end{tabular}

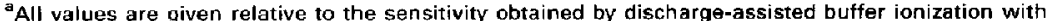
ammonium acetate (= $100 \%$ ) (average of at least three injections).

${ }^{6}$ All experiments are performed under identical experimental conditions, that is, $T_{v}=202{ }^{\circ} \mathrm{C} 1 \cong 95 \%$ vaporizationl, $7_{g}-235{ }^{\circ} \mathrm{C}$; direct flow injection; amount injected, 500 ng; carrier stream methanol : water $=50: 50(\mathrm{v} / \mathrm{v})$ with $c_{s}=70 \mathrm{mM}$ after postcolumn addition of reagent solution; see also Experimental section.

Proton affinity in kilojoules per mole

${ }^{\circ} \mathrm{SMCl}=$ solvent-mediated $\mathrm{Cl}$.

${ }^{e}$ DATSP $=$ discharge-assisted buffer ionization.
} 


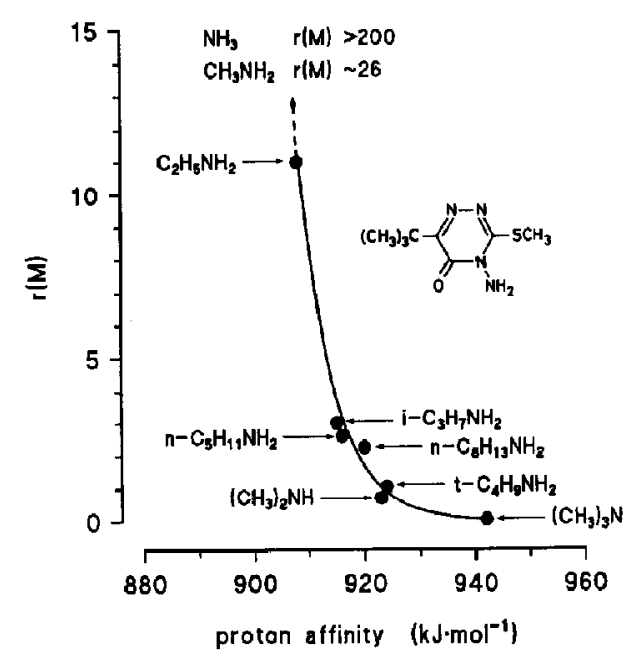

Figure 6. The dependence of adduct formation in TSP spectra on the proton affinity of the reagent ions. The relationship is shown for metribuzine; $r(\mathrm{M})=I\left(\mathrm{MH}^{+}\right) / I\left(\mathrm{M} \cdot\right.$ adduct $\left.^{+}\right)$. For details, refer to the text.

enhanced and comparable to that achieved with pure ammonium acetate, the POD substitution of chlorotriazines is almost completely suppressed.

Finally, if unknown compounds in real samples are identified by normal TSP-MS in a first step, the additional cluster formation described above is useful to confirm this identification in a second step.

\section{Phenylureas}

FRAGMENTATION. $N, N$-dimethyl-phenylureas show characteristic $[\mathrm{M}-11]^{+},[\mathrm{M}-28]^{+}$, and (less intense) $[\mathrm{M}-45]^{+}$ions under discharge-assisted ammonium acetate ionization. These ions are due to the isocyanate formed from the thermally labile phenylureas and they probably correspond to the $\left[\mathrm{M}-\mathrm{HN}\left(\mathrm{CH}_{3}\right)_{2}+\mathrm{NH}_{3}\right.$. $\left.\mathrm{NH}_{4}\right]^{+},\left[\mathrm{M}-\mathrm{HN}\left(\mathrm{CH}_{3}\right)_{2}+\mathrm{NH}_{4}\right]^{+}$, and $[\mathrm{M}-$ $\left.\mathrm{HN}\left(\mathrm{CH}_{3}\right)_{2}+\mathrm{H}\right]^{+}$ions. 'Thermal decomposition of trisubstituted urea pesticides under gas chromatographic conditions has been reported [24].

The unusual adduct ion lisocyanate $\left.+\mathrm{NH}_{3} \mathrm{NH}_{4}\right]^{+}$ in the TSP spectra was also reported by Cairns and
Siegmund for neburon [25]. Generally, isocyanates exhibit less intense proton adducts due to their low proton affinity. $\mathrm{NH}_{3} \mathrm{NH}_{4}^{+}$adduct ions of isocyanates were also observed in the TSP spectra of carbamates, for example, in the case of desmedipham, where the ion at $m / z 154$ reported previously [6] probably corresponds to the $\mathrm{NH}_{3} \mathrm{NH}_{4}^{+}$adduct ion of phenylisocyanate. Alternatively, the structure of the [isocyanate $\left.+\mathrm{NH}_{3} \mathrm{NH}_{4}\right]^{+}$ion can be assigned to $\left[\mathrm{RNHCONH}_{2}\right.$. $\mathrm{H} \cdot \mathrm{NH}_{3} \mathrm{I}^{+}$, which may be formed from the reaction between isocyanate and ammonia or ammoniumcontaining species in the reagent flow followed by ionization via ammonium attachment.

However, the relative abundance of isocyanate-related ions in the spectra of $N, N$-dimethyl-phenylureas is rather low as compared to the quasimolecular ions and usually does not exceed $10 \%$. Furthermore, in most cases the protonated amine formed is much more intense. Particularly the TSP spectra of N,N-dimethylphenylureas show ions due to protonated dimethylamine $(\mathrm{m} / \mathrm{z} 46)$ with relative abundances up to $80 \%$. Scheme I shows the different ionic species observed, where only the proton adducts of the decomposition products are represented. These ions are summarized in Table 5 for several phenylureas. (In addition, this table contains the results obtained by APCI, ESI, and FAB ionization as discussed below.) Although these ions are less specific, they can be used as confirmatory ions in combination with SIM, because no other intense fragment ions are available under normal operating conditions and no interfering signal is present in the reagent ion spectra of methanol-waterammonium acetate mixtures at $m / z$ 46. An example for a confirmatory analysis of phenylureas in a real sample has already been shown in Figure 3.

The amount of decomposition strongly depends on the temperature, both $T_{g}$ and $T_{v}$. As shown by Cairns and Siegmund [25] for neburon, this fragmentation is probably due to a decomposition of the neutral ureas in the vaporizer probe prior to ionization. Surprisingly, of the two possible products formed by this decomposition process, predominantly one product is observed as an ionized species under our experimental conditions, viz. $m / z$ 46. Whereas the relative abundance of the cationized isocyanates is low in each case and does
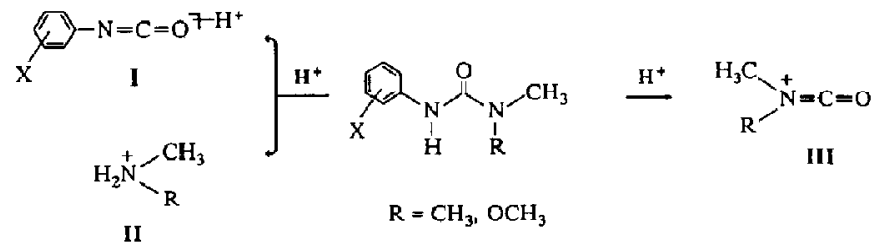

$\begin{array}{lll}\text { diuron: } & \mathrm{I}=m / 2 & 188,205,222 \\ \text { monolinuron: } & \mathrm{I}=m / z & 154,171,188\end{array}$

II $=m / z \quad 46$

II $=m / z \quad 62$

III $=m / z \quad 72$

III $=m / z 88$ 
Table 5. Major ions observed for several phenylureas using various LC-MS ionization techniques ${ }^{\mathrm{a}}$

\begin{tabular}{|c|c|c|c|c|c|c|}
\hline Compound & Ionization & {$[\mathrm{MII}]^{+} /[\mathrm{M} \cdot \mathrm{A}]^{+\mathrm{b}}$} & $\begin{array}{l}{\left[\mathrm{PheNCO}+\mathrm{H}^{+} /\right.} \\
{[\mathrm{PheNCO}+\mathrm{A}]^{+}}\end{array}$ & {$\left[\mathrm{H}_{2} \mathrm{~N}\left[\mathrm{CH}_{3} / \mathrm{R}\right]^{+\mathrm{c}}\right.$} & {$\left[\mathbf{R}\left(\mathrm{CH}_{3}\right) \mathrm{NCO}^{+}\right.$} & Other ions \\
\hline Chlorbromuron & APCI & $293(100)$ & - & $62(1)$ & $88(2)$ & \\
\hline \multirow[t]{3}{*}{$M_{n}=292$} & ESI & $293(100)$ & - & - & $88(5)$ & \\
\hline & $\mathrm{FAB}$ & $293(100) / 315(10)$ & - & $62(10)$ & $88(5)$ & $206\{10\}$ \\
\hline & TSPd & $293(100) / 310(20)$ & $232(3)$ & $62(2)$ & - & $215(15) .151(45)$ \\
\hline Chlorotoluron & APCI & $213(100)$ & - & $46(1)$ & $72(10)$ & $148(5)$ \\
\hline \multirow[t]{3}{*}{$M_{n}=212$} & ESI & $213(100)$ & - & - & $72(5)$ & \\
\hline & $\mathrm{FAB}$ & $213(100)$ & - & $46(8)$ & $72(40)$ & \\
\hline & TSP & $213(100) / 230(5)$ & $185(7) / 202(5)$ & $46(45)$ & - & $179(5)$ \\
\hline Difenoxuron & $\mathrm{APCl}$ & $287(100)$ & - & $46(1)$ & $72(5)$ & $123\{5\}$ \\
\hline \multirow[t]{3}{*}{$M_{n}=286$} & ESI & $287(100)$ & - & - & $72(4)$ & \\
\hline & FAB & $287(100) / 309(10)$ & - & - & $72(22)$ & $241(20), 123(15)$ \\
\hline & TSP & $287(100)$ & - & $46(39)$ & - & $216(40)$ \\
\hline Diuron & $\mathrm{APCl}$ & $233(100)$ & $222(5)$ & $46(3)$ & $72(15)$ & $278(10)$ \\
\hline \multirow[t]{3}{*}{$M_{n}=232$} & ESI & $233(100) / 255(10)$ & - & - & $72(12)$ & \\
\hline & $\mathrm{FAB}$ & $233(100)$ & - & $46(5)$ & $72(45)$ & $386(8)$ \\
\hline & TSP & $233(100)$ & $188(2) / 205(5) / 222(3)$ & $46(50)$ & - & $199(5)$ \\
\hline Isoproturon & $\mathrm{APCl}$ & $207(100)$ & - & $46(3)$ & $72(12)$ & \\
\hline \multirow{3}{*}{$M_{n}=206$} & ESI & $207(100)$ & - & - & $72(5)$ & \\
\hline & $\mathrm{FAB}$ & $207(100) / 229(90)$ & - & $46(15)$ & $72(20)$ & $191(20), 146(10)$ \\
\hline & TSP & $207(100) / 224(5)$ & $179(10) / 196(2)$ & $46(50)$ & - & $252(4)$ \\
\hline Linuron & $\mathrm{APCl}$ & $249(100) / 266(5)$ & - & $62(2)$ & $88(2)$ & \\
\hline \multirow[t]{3}{*}{$M_{n}=248$} & ESI & $249(100)$ & - & - & $88(4)$ & \\
\hline & FAB & $249(100) / 271(10)$ & - & $62(10)$ & $88(5)$ & \\
\hline & TSP & $249(100) / 266(20)$ & $205(5)$ & $62(3)$ & $88(1)$ & $219(17)$ \\
\hline Metobromuran & $\mathrm{APCl}$ & $259(100)$ & - & - & $88(4)$ & \\
\hline \multirow[t]{3}{*}{$M_{n}=258$} & ESI & $259(100)$ & - & - & - & \\
\hline & $\mathrm{FAB}$ & $259(100\} / 281(10)$ & - & $62(8)$ & $88(5)$ & \\
\hline & TSP & $259(100) / 276(10)$ & $215(3)$ & $62(2)$ & - & $229(5), 151(20)$ \\
\hline Metoxuron & $\mathrm{APCl}$ & $229(100)$ & - & $46(3)$ & $72(18)$ & \\
\hline \multirow[t]{3}{*}{$M_{n}=228$} & ESI & $229(100) / 251(20)$ & - & - & $72(5)$ & \\
\hline & FAB & $229(100) / 251\langle 10\rangle$ & - & $46(8)$ & $72(50)$ & $183(10)$ \\
\hline & TSP & $229(100) / 246(5)$ & $184(2) / 201(10) / 218(3)$ & $46(35)$ & - & $195(10), 185(5)$ \\
\hline Manolinuron & APCI & $215(100) / 232(5)$ & - & $62(2)$ & $88(3)$ & $126(10)$ \\
\hline \multirow[t]{3}{*}{$M_{n}=214$} & ESI & $215(100) / 232(5)$ & - & - & $88(3)$ & \\
\hline & FAB & $215(100) / 237(15)$ & - & $62(5)$ & $88(5)$ & \\
\hline & TSP & $215(100) / 232(10)$ & $171(3) / 188(2)$ & $62(2)$ & - & $185(5)$ \\
\hline & $\mathrm{APCl}$ & $199(100)$ & - & $46(1)$ & $72(20)$ & \\
\hline \multirow[t]{3}{*}{$M_{n}=198$} & ESI & $199(100)$ & - & - & $72(5)$ & \\
\hline & FAB & $199(100) / 221(40)$ & - & $46(2)$ & $72(55)$ & \\
\hline & TSP & $199(100) / 216(4)$ & $171(10) / 188(5)$ & $46(55)$ & - & \\
\hline
\end{tabular}

\footnotetext{
${ }^{3}$ The ion abundances (in parentheses) are expressed as a percentage of relative abundance. The experimental conditions are described in the Experimental section.

${ }^{b}$ Cluster Ion $[\mathrm{M} \cdot \mathrm{A}]^{\prime}: \mathrm{A}=\mathrm{NH}_{4}, \mathrm{NH}_{3} \mathrm{NH}_{4}^{+}$, or $\mathrm{Na}^{+}$

${ }^{c} \mathrm{R}=-\mathrm{CH}_{3}$ or $-\mathrm{OCH}_{3}$.

Discharge-assisted buffer ionization.
}

not depend on $T_{v}$ even at a very high vaporizer temperature $\left(T_{v}-250^{\circ} \mathrm{C}\right)$. This is in contrast to the results of Cairns and Siegmund [25], who reported the abundant formation of cationized isocyanate. This divergence probably is duc to the different design of the TSP interfaces. Further experiments with a FinniganMAT TSP source revealed a major abundance of the isocyanate in the TSP spectrum of diuron $(m / z 205$ and 222). Moreover, the ion abundance of diuron is strongly dependent on the vaporizer temperature with this source, indicating a decomposition prior to ionization (see Figure $7 a$ for $T_{1}^{\prime}=70$ and $95^{\circ} \mathrm{C}$ ). Careful adjustment of the interface temperatures enables reproducible results and the thermally assisted degrada- tion can be used to generate structurally specific ions in the TSP spectrum. An interlaboratory comparative study of several carbamates and phenylureas with respect to ion formation and sensitivity obtained with different TSP interfaces of several manufacturers has been conducted under well defined comparative experimental conditions. Results of this study are now under development and will be presented in a subsequent article.

So far, we have assumed that phenylureas undergo thermal decomposition of the neutral molecule to form the isocyanate and the corresponding amine, which are protonated in a second step. To confirm this assumption, additional CAD experiments were performed with 

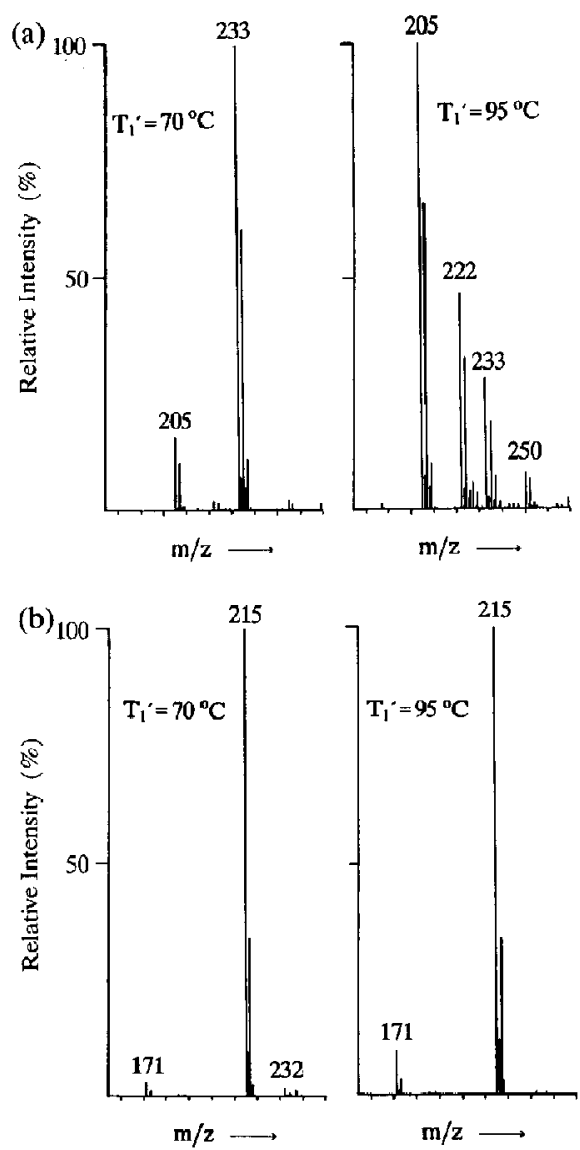

Figure 7. Thermal degradation of phenylureas to their isocyanates and variation of ion abundances in the TSP spectra of $N, N$-dimethylureas and $N$-methoxy- $N$-methylureas with vaporizer temperature. (a) Diuron and (b) monolinuron. Amount injected: $100 \mathrm{ng}$.

diuron and monolinuron. The results of these measurements are summarized in Table 6. CAD spectra of phenylureas already have been discussed by others $[20,25,26]$. However, the reported results are, in part, contradictory. Thus differences are observed as compared to the results of Niessen et al. [20], who only reported $m / z 72$ (III) in the TSP MS/MS spectrum of diuron, whereas Cairns and Siegmund [25] observed abundant protonated amine (II) (35\% relative abundance) in the CAD spectra of neburon, and McFadden and Lammert [26] found $m / z 46(50 \%)$ and $m / z 72$ $(100 \%)$ in TSP CAD experiments with difenoxuron and isoproturon. Our CAD results are in agreement with the latter, as can be seen from Table 6. The CAD spectra demonstrate, at least for diuron, that decomposition not only of the neutral molecule, but also the protonated molecule, may lead to the formation of I and II in the TSP source (apparently in the case of the Vestec source).

The TSP spectra of $N$-methyl- $N$-methoxy-phenylureas show only weak intensities of the corresponding amine at $m / z 62$ and of the isocyanate. Even an increase of $T_{z}$, has only a slight effect on the fragment ion abundance (Figure $7 \mathrm{~b}$ ). Generally, $N$-methyl $-N$ methoxy-phenylureas are more stable and are even amenable to on-column injection GC analysis. Probably, the basicity of the $N, N$-dialkylated nitrogen atom is decreased by the additional oxygen atom in such a way that protonation most likely occurs at the phenylbound nitrogen of the urea function. Figure 8 demonstrates the stability of $N$-methoxy- $N$-methyl-phenylureas in comparison to their corresponding $N$, $\mathrm{N}$-dimethyl-phenylureas. The figure shows a timescheduled TSP SIM chromatogram of three $\mathrm{N}$-methyl$\mathrm{N}$-methoxy-phenylureas (monolinuron, linuron, and chlorbromuron) and three $N, N$-dimethyl-phenylureas (fenuron, monuron, and diuron) under typical operating conditions $\left(T_{8} \approx 235^{\circ} \mathrm{C}\right.$ and $\left.T_{v} \approx 200{ }^{\circ} \mathrm{C}\right)$. Although the latter compounds exhibit abundant ions of type II $(m / z 46)$, the corresponding ion for $N$ methoxy-type phenylureas at $m / z$ is of very low abundance.

Ions corresponding to structure III at $m / z 72$ or 88 are missing in the discharge-assisted buffer ionization spectra, although the fragment at $m / z 72$ apparently has a low appearance energy [20].

OTHER IONIZATION TECHNIQUES. With ESI and FAB ionization, the fragmentation is reversed with respect to the structure: the ions at $m / z 46$ and 62 are less intensive or even absent whereas species III (Scheme I)

Table 6. Fragments obtained by collision-activated dissociation of ions in the TSP mass spectra of diuron and monolinuron ${ }^{a}$

\begin{tabular}{|c|c|c|c|}
\hline \multirow[b]{2}{*}{ Compound } & \multicolumn{2}{|c|}{ Precursor ion } & \multirow{2}{*}{$\frac{\text { Daughter ions }}{\mathrm{m} / \mathrm{z} \text { (\% relative abundance) }}$} \\
\hline & Tentative structure & $m / z$ & \\
\hline \multirow[t]{3}{*}{ Diuron } & {$[\mathrm{MH}]^{+}$} & 233 & $188(3), 160(8), 72(100), 46(8)$ \\
\hline & [isocyanate $\left.\cdot \mathrm{H} \cdot\left(\mathrm{NH}_{3}\right)_{2}\right]^{+}$ & 222 & $205(53), 188(13), 162(100), 160(15), 127(85)$ \\
\hline & [isocyanate $\left.\cdot \mathrm{H} \cdot \mathrm{NH}_{3}\right]^{+}$ & 205 & $205(20), 188(15), 162(100), 160(10), 127(80)$ \\
\hline \multirow[t]{2}{*}{ Manolinuron } & {$[\mathrm{MH}]^{+}$} & 215 & $\begin{array}{l}183(5), 148(45), 146(10), 128(34), 126(100), \\
119(10), 99(20), 90(5), 62(10), 60(5)\end{array}$ \\
\hline & [isocyanate $\left.\cdot \mathrm{H} \cdot \mathrm{NH}_{3}\right]^{+}$ & 171 & $\begin{array}{l}171(3), 154(3), 128(40), 126(22), 111(2) \\
93(100)\end{array}$ \\
\hline
\end{tabular}

${ }^{\mathrm{a}} \mathrm{COFF}=-20 \mathrm{~V}$; collision cell pressure: argon, $1.3 \times 10^{-3}$ torr. 


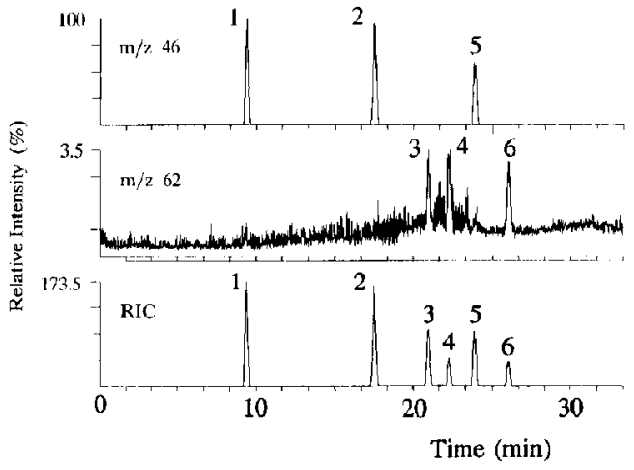

Figure 8. Dischargc-assistcd TSP SIM chromatogram of three $N, N$-dimethyl-phenylureas and three $N$-methoxy- $N$-methylphenylureas by simultaneously recording the $[\mathrm{MH}]^{+}$ions and their degradation products at $m / z 46$ and 62. Peak assignments: 1. fenuron; 2, monuron; 3 , monolinuron; 4, diuron; 5 , linuron; 6 , chlorbromuron. Injected amount: 50 ng each.

is favored at least for the $N, N$-dimethylureas (Table 5). This behavior is expected because less thermal stress occurs during ionization via ESI and FAB as compared to TSP. Surprisingly, this behavior is also observed with APCI by using ammonium acetate by applying the same gradient and buffer conditions as described for TSP operation (see Experimental section). Although ionization conditions are very similar to thermospray, no intense ions at $m / z 46$ and 62 are observed with APCI in contrast to TSP ionization. However, when using ESI and APCI, confirmation of N,N-dimethylphenylureas during chromatographic analysis is quite possible by using the ion at $m / z 72$ (species $\mathrm{HI}$ ). In the case of the Finnigan-MAT APCI and ESI source, the intensity of this ion can be strongly enhanced for all investigated $N, N$-dimethyl-phenylureas if a collision offset is applied to the built-in octopole rods. For example, if $30 \mathrm{~V}$ are applied, the intensity of $m / z 72$ amounts to $70-95 \%$ of the total ion current.

Also under ESI and APCI conditions, $N$-methyl-Nmethoxy-phenylureas are more stable and show only low fragmentation. That is, the ion at $m / z 88$ (species III) is only formed with low abundances $(<1 \%)$ similar to the ion $m / z 62$ in the TSP mode.

AMINE CLUSTERS. The postcolumn addition of alkylated amines in the TSP mode, as described in the previous section, was successfully applied to several carbamates and phenylureas (an example is shown in the following section). In general, most carbamates and phenylureas investigated exhibit the [M. $\mathrm{H} \cdot$ ancine $]^{+}$ ion instead of the protonated or ammonium-cationized molecule as base peaks because their proton affinities are lower than those of the amines (see previous section for details). In addition, phenylureas give POD reactions that enhance structural information. The dimethylated phenylureas undergo a carbonyl reaction, that is, the $N, N$-dimethyl group is in part replaced by the added aliphatic amine: $\mathrm{Phe}-\mathrm{NH}-\mathrm{CO}-$ $\mathrm{N}\left(\mathrm{CH}_{3}\right)_{2}+\mathrm{H}_{2} \mathrm{NC}_{n} \mathrm{H}_{2 n+1} \rightarrow$ Phe- $\mathrm{NH}-\mathrm{CO}-\mathrm{NHC}_{n}$ $\mathrm{H}_{2 n+1}+\mathrm{HN}\left(\mathrm{CH}_{3}\right)_{2}$. Thus $\left[\mathrm{M}_{s} \cdot \mathrm{H} \cdot \text { amine }\right]^{+}$ions are formed in addition to the $\left[\mathrm{M} \cdot \mathrm{H} \cdot\right.$ amine $^{+}$ions, which represent the base peak in each case. For example, diuron $\left(M_{n}=232\right)$ exhibits these ions at $m / z 306$ ( $i-\mathrm{C}_{3} \mathrm{H}_{7} \mathrm{NH}_{2}, 70 \%$ relative abundance), $m / z 334$ ( $t$ $\left.\mathrm{C}_{4} \mathrm{H}_{9} \mathrm{NH}_{2}, 3 \%\right), m / z 362\left(n-\mathrm{C}_{5} \mathrm{H}_{11} \mathrm{NH}_{2}, 45 \%\right)$, and $m / z 390\left(n-\mathrm{C}_{6} \mathrm{H}_{13}, 55 \%\right)$. The low reaction yield observed in the case of tert-butylamine is probably due to a steric hindrance.

Sulfonylureas. For the confirmation of sulfonylureas no special technique is necessary because these compounds usually exhibit a wide spectrum of intense fragments in the TSP mode, whereas the quasimolecular ion is of very low intensity or even absent [27]. This situation is most probably due to thermal degradation reactions in the vaporizer probe [21]. We have investigated eight sulfonylureas by various ionization techniques. All compounds exhibit thermal and mass spectrometric dissociation in the TSP mode. Generally, characteristic ions from both moieties of the sulfo-

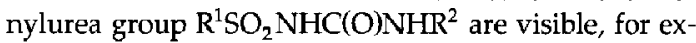
ample, $\left[\mathrm{R}^{1} \mathrm{SO}_{2}\right]^{+},\left[\mathrm{R}^{1} \mathrm{SO}_{2} \mathrm{NH}_{2}+\mathrm{H}\right]^{+},\left[\mathrm{R}^{1} \mathrm{SO}_{2} \mathrm{NH}_{2}+\right.$ $\left.\mathrm{NH}_{4}\right]^{+},\left[\mathrm{R}^{2} \mathrm{NH},+\mathrm{H}\right]^{+},\left[\mathrm{R}^{2} \mathrm{NCO}+\mathrm{H}\right]^{+}$, and $\left[\mathrm{R}^{2} \mathrm{NCO}\right.$ $\left.+\mathrm{NH}_{4}\right]^{+}$. For example, metsulfuron-methyl (nominal mass 381) exhibits these ions at $m / z 199,216,233,141$, 167 , and 184 in the TSP spectrum. No ions corresponding to the intact molecule were observed. As expected, the APCI spectrum (plus ammonium acetate) of metsulfuron-methyl is consistent with the TSP results, although an abundant protonated molecule at $\mathrm{m} / \mathrm{z}$ 381 was additionally observed (70\% relative abundance). The ESI and FAB spectra of metsulfuron-methyl exhibit only quasimolecular ions. In addition to the protonated molecule (ESI, $50 \%$; FAB, 30\%) both spectra show abundant sodium-cationized ions at $m / z 404$ $\left(=[\mathrm{M}+\mathrm{Na}]^{+}\right.$; ESI, $\left.100 \% ; \mathrm{FAB}, 55 \%\right)$ and $426(=[\mathrm{M}$ $-\mathrm{H}+2 \mathrm{Na}]^{\prime} ; \mathrm{ESI}, 15 \%$; FAB, 100\%).

An example of the combined on-line trace enrichment and TSP LC-MS analysis of sulfonylureas in aqueous samples is shown in Figure 9. More details concerning the on-line solid-phase extraction technique are reported elsewhere [28].

\section{Amines, anilides, and organophosphorous compounds}

FRAGMENTATION. The TSP mass spectra of most of the investigated anilides and $N$-substituted amines (Table 1) contain significantly more fragmentation than those of the phenylureas and triazines. This is demonstrated in Figure 10a, where the discharge-assisted buffer ionization spectrum of the anilide butachlor is shown. The relative abundance in the TSP spectra of 

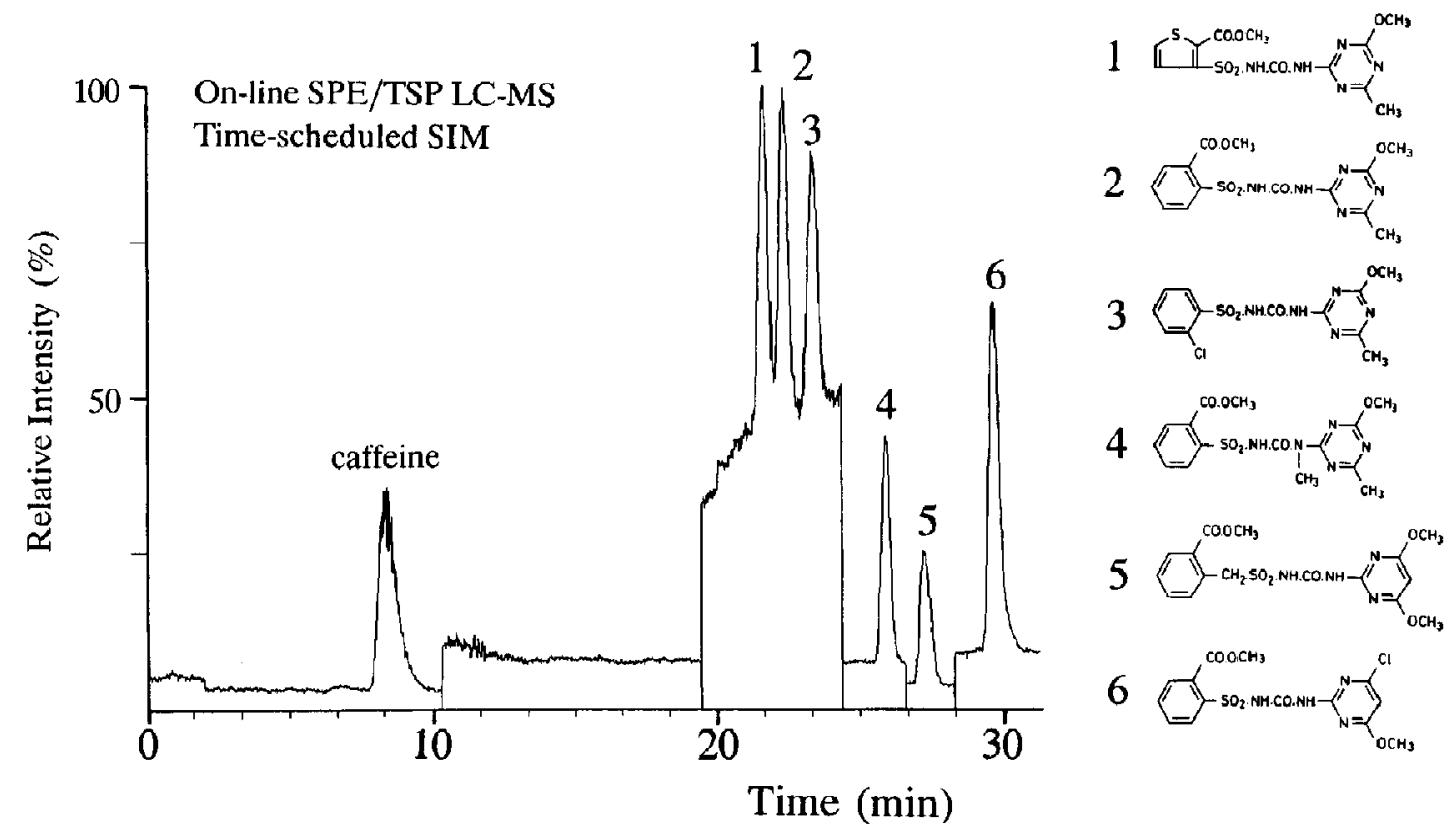

Figure 9. On-line trace enrichment TSP LC-MS traces for $100 \mathrm{~mL}$ of a drinking water sample spiked with a mixture of six sulfonylureas at $150 \mathrm{ng} / 100 \mathrm{~mL}$. Time-scheduled SIM traces of the $\mathrm{R}^{2} \mathrm{NH}_{3}^{+}$ ions formed from the dissociation of the sulfonylureas (the intensity of these $\mathrm{R}^{2} \mathrm{NH}_{3}^{+}$ions amount to $60-90 \%$ of the TIC; $\mathbf{R}^{2}=N$-heterocyclic moiety). Peak assignments: 1 , thifensulfuron-methyl; 2 , metsulfuron-methyl; 3 , chlorsulfuron; 4 , tribenuron-methyl; 5 , bensulfuron-methyl; 6 , chlorimuronmethyl.

butachlor and other anilides varies greatly with interface temperatures, as previously reported by us [7] for alachlor, especially for chloroacetic acid $N$-alkoxymethylanilides, (e.g., alachlor and butachlor).

Such observations can be rationalized in terms of "chemical dissociation," where the analyte molecule degrades prior to ionization, probably induced by buffer salt, heat, or solvent followed by ionization of the degradation products, sometimes with successive fragmentations. This scenario is especially valid for alachlor and butachlor, where the discharge-assisted buffer ionization spectra mainly exhibit quasimolecular ions, that is, $[\mathrm{MH}]^{+}$and $\left[\mathrm{MH} \cdot \mathrm{NH}_{3}\right]^{+}(m / z 270$, 287 , and 312,329 , respectively) for $T_{s}<200{ }^{\circ} \mathrm{C}$, whereas for $T_{8}>250{ }^{\circ} \mathrm{C}$ the base peak at $m / z 226$ is due to a thermolysis reaction prior to ionization (Scheme II). These particular ions do not occur in the corresponding $\mathrm{FAB}$ and ${ }^{252} \mathrm{Cf}$ plasma desorption spectra, nor do they appear in the electrospray or CAD spectra (Figure 10b-d). The product ion spectrum of the precursor ion $\mathrm{m} / z 312$ exhibits the ions at $\mathrm{m} / z 238$ and 162. The ESI tandem mass spectrometry spectra of alachlor, dimethachlor, and metolachlor follow the same fragmentation mechanisms. (The corresponding ions are explained in the following text.) The described temperature dependence readily can be used for confirmation purposes.
Not all abundant ions in the TSP spectra are due to a thermal degradation of the neutral molecule followed by ionization. Comparison of the FAB, ESI, ${ }^{252} \mathrm{Cf}-\mathrm{PD}$, and, in particular, the CAD spectrum of the quasimolecular ion reveals that the protonated molecule also degrades to give abundant fragments. Thus initial protonation at the ether oxygen atom with neutral loss of alcohol produces resonance-stabilized carbenium-imminium ions [alachlor and butachlor: $m / z 238$ (see Scheme II); dimethachlor: $m / z$ 224; metolachlor: $\mathrm{m} / \mathrm{z} 252$ and 238 (loss of dimethylether)]. In a second step, these ions probably undergo further loss of neutral ketene to give a second carbenium-imminium ion in the FAB, TSP, and ${ }^{252} \mathrm{Cf}-\mathrm{PD}$ as well as in the CAD spectra of the $[\mathrm{MH}]^{+}$ion (ESI MS/MS: $m / z 162$ for alachlor and butachlor; refer to Scheme II; $m / z 148$ for dimethachlor and $m / z 176$ for metolachlor), whereas this fragmentation is not observed in the ESI spectra. Smaller alkyl substituents between the nitrogen and the ether oxygen atom seem to enhance the primary fragmentation from the molecular ion: whereas fragments from the molecular ion corresponding to the loss of alcohol are absent in the TSP spectra of dimethachlor and metolachlor, they are also less intense in the corresponding ESI, FAB, and ${ }^{252} \mathrm{Cf}-\mathrm{PD}$ spectra (Table 7). The formation of the secondary and tertiary carbenium-imminium ions is probably not fa- 

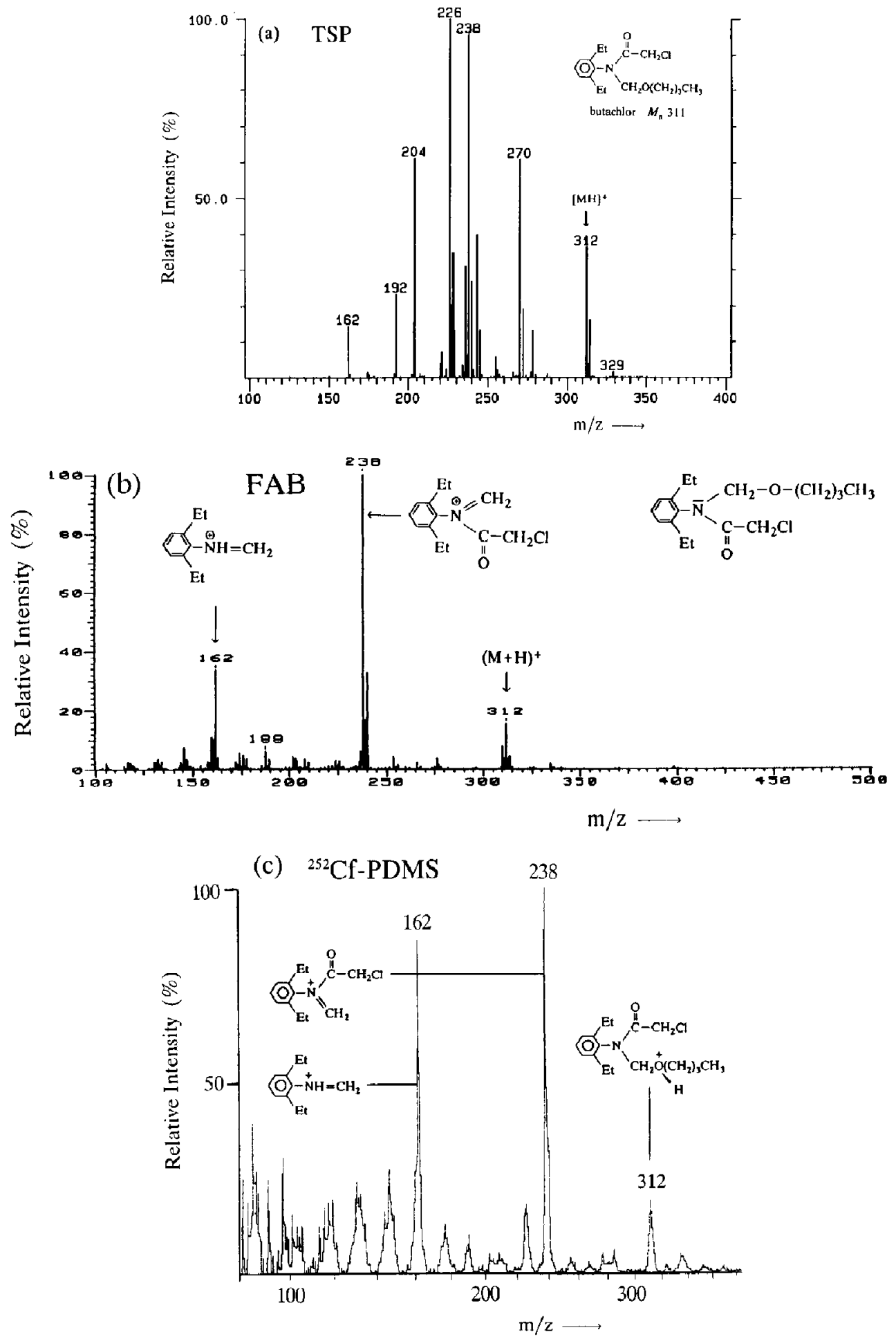

Figure 10. Mass spectra of butachlor obtained by various ionization techniques: (a) discharge-assisted thermospray (for peak assignment, refer to Scheme 2); (b) fast-atom-bombardment; (c) ${ }^{252} \mathrm{Cf}$ plasma desorption; (d) electrospray; (e) collision-activated dissociation. 

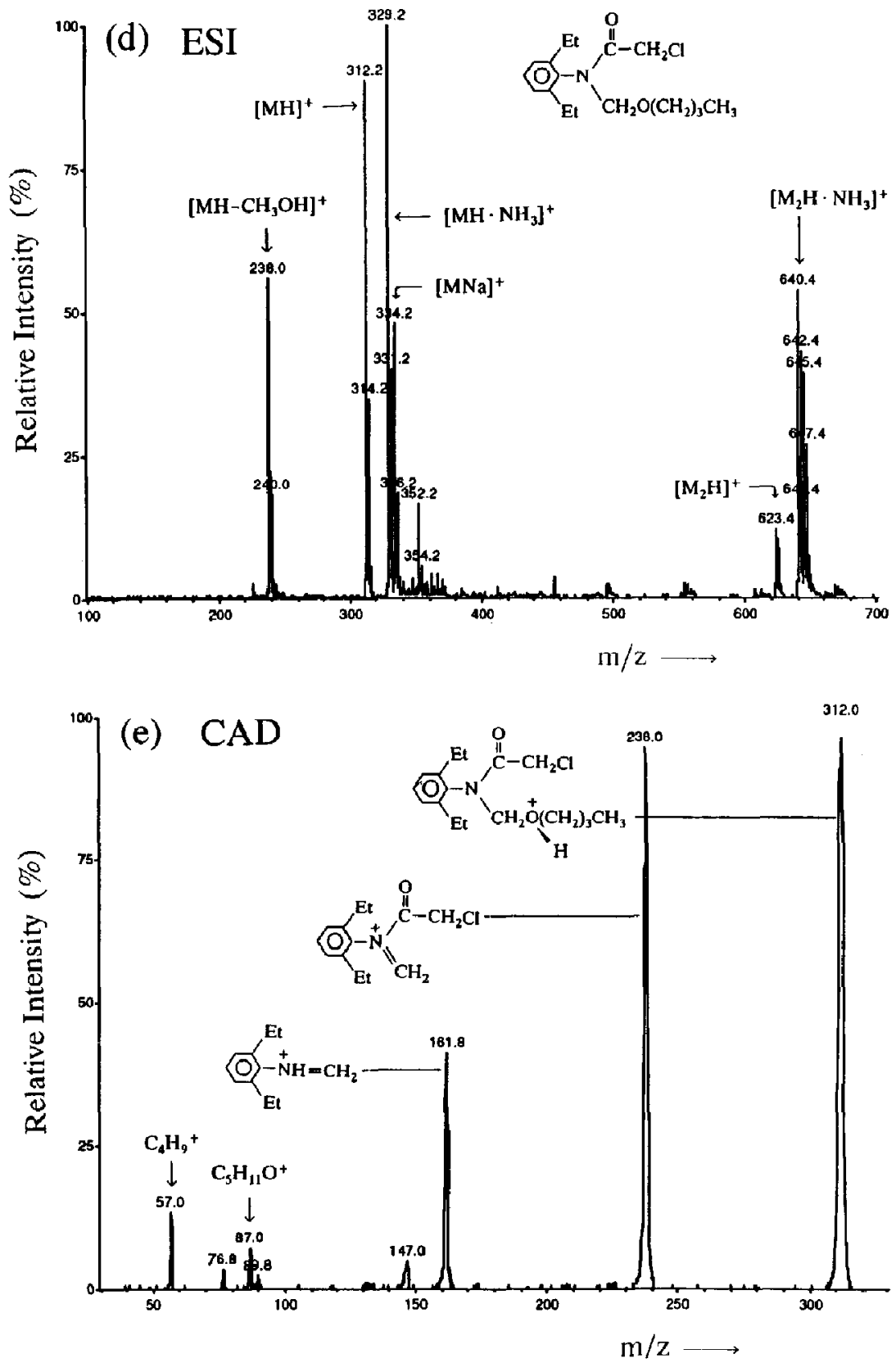

Figure 10. (Continued)

vored because an additional 1,2-hydrid shift is necessary.

This mechanism is also operative for structurally different anilides. For example, the TSP spectra of metazachlor exhibit an ion at $m / z 210$ that is probably due to a neutral loss of pyrazole after protonation at $N-1$ of the pyrazole moiety.
DECHLORINATION. The interise peak at $m / z 204$ with no chlorine isotope pattern in the discharge-assisted buffer ionization spectra of butachlor (Figure 10a) probably corresponds to a chlorine-hydrogen substitution (Scheme II). Generally, the discharge-assisted buffer ionization and solvent-mediated CI spectra of all investigated anilides exhibit characteristic 


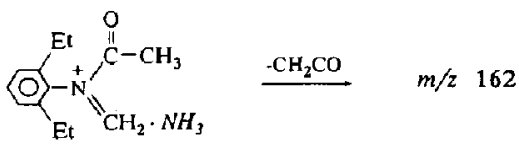

$m / z 204(221)$

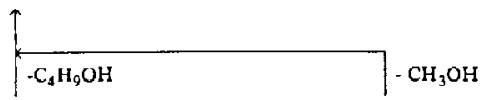<smiles>CCc1ccc(CC)n1CC(C)=O</smiles>

$m / z \quad 278$

$\left\{\begin{array}{l}\mathrm{I} \cdot \cdot-\mathrm{HCl} \\ +\mathrm{H} \cdot \\ \left(\mathrm{NH}_{4} \cdot \mathrm{OH}_{2}\right)^{+}\end{array}\right.$<smiles></smiles>

$m / z \quad 236$

hydrolysis/thermolysis $m / z \quad 150$<smiles>CCCC=O</smiles><smiles>CCc1cccc(CC)c1NC(C)=O</smiles>

$m / z 192(209)$

$$
\left\{\begin{array}{l}
+\mathrm{H}, \cdot \mathrm{HCl} \\
+\mathbf{H}^{\cdot} \\
\left(\mathrm{NH}_{4} \cdot \mathrm{OH}_{2}\right)^{+}
\end{array}\right.
$$<smiles>CCc1cccc(CC)c1NC(=O)CCl</smiles><smiles></smiles><smiles>CCc1cccc([NH+](CC)C(=O)CCl)c1N</smiles>

$m / z 226$ (243)

$m / z \quad 270(287)$ $\cdot \mathrm{CH}_{3} \mathrm{OH}$<smiles>O=CCCCC=O</smiles><smiles></smiles>

$m / z 238(255)$<smiles>CC(C)=O</smiles><smiles>C=[NH+]c1cccc(CC)c1CC</smiles>

$m / z \quad 162$<smiles>CCc1cccc(CC)c1N</smiles>

$m / z \quad 150$

Scheme II

$[\mathrm{MH}-34]^{+}$and $[\text {fragment }-34]^{+}$ions for all chlorinecontaining species (see Figure 10a and Table 7). This substitution reaction is not observed in the buffer ionization mode [7] or via ESI, FAB, and ${ }^{252} \mathrm{Cf}-\mathrm{PD}$ ionization. This reaction probably is due to a reductive dehalogenation involving replacement of a halogen atom by a hydrogen atom. The reaction also occurs with other compound classes such as chlorotriazines and phenylureas as already shown in Figures 4 and 5 . As an example, the comparison of discharge-assisted buffer ionization and TSP mode is demonstrated in
Figure 11, where the spectra of diuron are shown with either discharge-on or discharge-off operation but otherwise identical experimental conditions.

Generally, the amount of dechlorination is higher for aliphatic-bound chlorines, for example, higher for chloroanilides (dechlorination ranges from 10 to 50\%) than for chlorine atoms bound to an aromatic ring $(1-10 \%)$. These reductive dehalogenations probably take place via a radical reaction prior to ionization [29. 30] induced by radicals that are formed from the plasma generated in a CI source (refer to Figure 11). 
Table 7. Major ions observed for chloroacetic acid $N$-alkoxy-methylanilides using various LC-MS ionization techniques ${ }^{\mathrm{a}}$

\begin{tabular}{|c|c|c|c|c|c|}
\hline Compound & Ionization & $\left.[\mathrm{MH}]^{+} / \mathrm{IM} \cdot \mathrm{A}\right]^{+\mathrm{b}}$ & {$[\mathrm{M}-\mathrm{X}+2 \mathrm{H}]^{+}$} & {$[\mathrm{MH}-\mathrm{ROH}]^{+}$} & Other ions \\
\hline Alachlor & ESI & $270(85) / 287(100)$ & - & $238(70)$ & $556(25)$ \\
\hline \multirow[t]{4}{*}{$M_{n}=\mathbf{2 6 9}$} & FAB & $270(28) /-$ & - & $238(100)$ & $188(10), 162(30)$ \\
\hline & TSP $^{\mathrm{c}}$ & $270(100) / 287(6)$ & $236(33)$ & $238(77)$ & $\begin{array}{l}243(28), 226(88), 204(37), 192(10) \\
162(10), 150(5)\end{array}$ \\
\hline & ${ }^{252} \mathrm{Cf}-\mathrm{PD}$ & $270(30) /-$ & - & $238(95)$ & $162(100)$ \\
\hline & CAD $^{d}$ & $270(100)$ & - & $238(80)$ & $162(68), 147(10), 45(15)$ \\
\hline Butachlor & ESI & $312(90) / 329(100) / 334(47)$ & - & $238(60)$ & $645(25), 640(50), 623(12)$ \\
\hline \multirow{4}{*}{$M_{n}=311$} & FAB & $312(18) / 334(3)$ & - & $238(100)$ & $162(45)$ \\
\hline & TSP & $312(37) / 329(3)$ & $278(15)$ & $238(95)$ & $\begin{array}{l}287(12), 270(63), 243(40), 226(100), \\
204(60), 162(10)\end{array}$ \\
\hline & ${ }^{252} \mathrm{Cf}-\mathrm{PD}$ & $312(13) /-$ & - & $238(100)$ & $162(65)$ \\
\hline & CAD & $312(100)$ & - & $238(98)$ & $162(45), 87(8), 57(12)$ \\
\hline Dimethachlor & ESI & $256(100) / 273 /(55) / 278(22)$ & - & 224(4) & $528(55), 511(20)$ \\
\hline \multirow[t]{4}{*}{$M_{n}=255$} & FAB & $256(100) / 278(40)$ & - & $224(54)$ & $197(15), 148(11), 59(8)$ \\
\hline & TSP & $256(100) /-$ & $222(38)$ & - & - \\
\hline & ${ }^{252} \mathrm{Cf}-\mathrm{PD}$ & $256(100) /-$ & - & $224(60)$ & $148(34), 132(50)$ \\
\hline & CAD & $256(100)$ & - & $224(67)$ & $148(28), 132(5), 105(5), 77(5)$ \\
\hline Metolachlor & ESI & $284(100) / 301(45)$ & - & $252(2)$ & - \\
\hline \multirow[t]{4}{*}{$M_{n}=283$} & FAB & $284(100) / 306(23)$ & - & $252(68)$ & $\begin{array}{l}238(30), 206(10), 176(13), 162(28) \\
122(18), 73(30)\end{array}$ \\
\hline & TSP & $284(100) /-$ & $250(33)$ & - & - \\
\hline & ${ }^{252} \mathrm{Cf}-\mathrm{PD}$ & $284(75) /-$ & - & $252(40)$ & $238(100), 162(50)$ \\
\hline & CAD & $284(98)$ & - & $252(100)$ & $212(10), 176(25), 73(11)$ \\
\hline
\end{tabular}

\footnotetext{
${ }^{a}$ The ion abundances (in parentheses) are expressed as a percentage of relative abundance. The experimental conditions are described in the Experimental section.

${ }^{b}$ Cluster ion $[\mathrm{M}-\mathrm{A}]^{+}: \mathrm{A}=\mathrm{NH}_{4}^{+}$or $\mathrm{Na}^{+}$

'Discharge-assisted buffer ionization. In the buffer ionization mode no $[M-X+2 H]^{+}$ions are observed! (See text.)

dPrecursor ions $[\mathrm{MH}]^{+}$are generated by ESI tandem mass spectrometry; amount injected: 6 ng. For experimental conditions, refer to Table 5 .
}

In the case of disubstituted and trisubstituted compounds, for example, for the trichlorinated aliphatic organophosphorous pesticides butonate and trichlorfon and the dichlorinated pesticide dichlorovos, all chlorine atoms are replaced successively under discharge-assisted buffer ionization (the spectra are not shown in this report), that is, $[\mathrm{M}-x \mathrm{Cl}+(x+1) \mathrm{H}]^{+}$ ions $(x=1,2$, and 3$)$ are observed with relative abundances of up to $50 \%$, whereas in the TSP mode, again, no reductive dechlorination was observed [7].

It is interesting that in the case of anilazine, which contains three chlorines, abundant signals corresponding to dechlorination are observed only for two chlorines in the discharge-assisted TSP spectra, whereas the $\left[\mathrm{M}_{\mathrm{s}}-3 \mathrm{Cl}+4 \mathrm{H}\right]^{+}\left(\mathrm{M}_{s}\right.$ substitution product obtained by POD) ion abundance is very low. Apparently, both chlorines that are bound to the $\mathrm{N}$ heterocyclic moiety are replaced favorably (Figure 5). However, diuron exhibits replacement of both phenylbound halogen atoms (Figure 11).

This behavior corresponds to findings of other authors, who report dehalogenations under CI conditions, for example, dechlorination reactions in the case of phenylureas [20]. Dehalogenations also reportedly occur as FAB-induced substitutions in the condensed phase via a free radical mechanism that precedes the ionization process, for example, with nucleosides [31, 32] and antibiotics [33]. Similar dehalogenations also are observed during ${ }^{252} \mathrm{Cf}$ plasma desorption and $\mathrm{FAB}$ ionization of 5-halouracils and thyroxine [34].

\section{Conclusions}

The purpose of the present work was to evaluate methods used for determination and confirmation of nitrogen-and phosphorus-containing pesticides by TSP LC-MS. After solid-phase extraction of aqueous water samples, pesticide residues readily can be identified, confirmed, and quantified at a concentration level of $<100 \mathrm{ng} \mathrm{L}^{-1}$ (which corresponds to the CEC drinking water limit). This level is achieved using gradient elution LC with time-scheduled SIM detection.

It has been shown that, through the combined use of several experimental parameters, both cationized molecules for molecular weight information and abundant fragment ions for structural confirmation from the TSP spectra can be obtained for the majority of the investigated pesticides. These parameters include a variation of the source and vaporizer temperature to induce thermal degradation and the use of different organic modifiers added postcolumn to the mobile phase. Thus, postcolumn on-line derivatization (POD) was achieved by adding different alkylated amines with varying proton affinities and nucleophilicities. In the case of chlorotriazines and several other $N$-heterocyclic compounds, this on-line derivatization led to chlorine substitution and amine adduct ion formation. Both processes can be used to enhance structural information and thus the specificity of the method. It is demonstrated for carbamates, phenylureas, and $N$ heterocyclic compounds that the proton affinity has a 


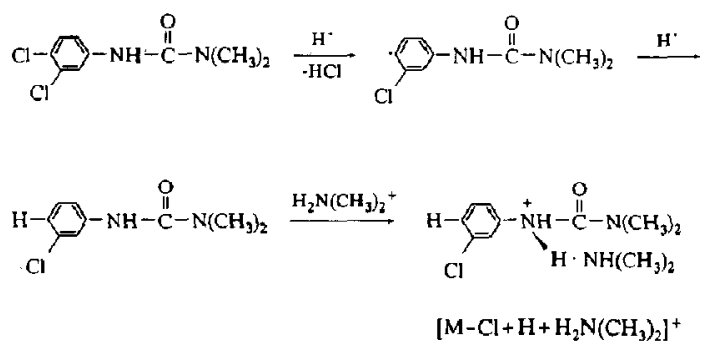

$\mathbf{a}$

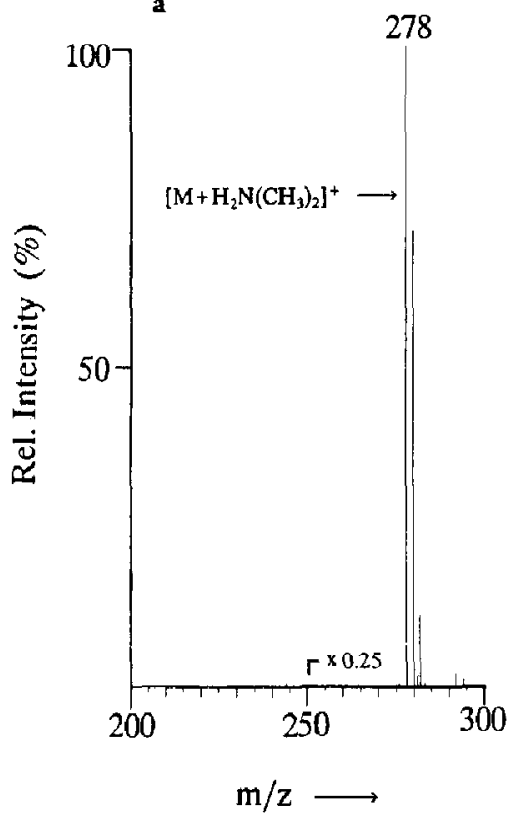

b

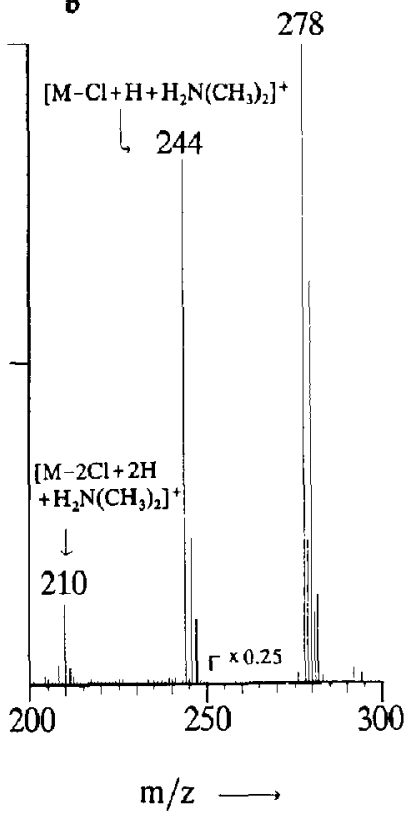

Figure 11. Comparison of ionization modes in the TSP analysis of diuron after POD with dimethylamine and proposed fragmentation pathway. (a) Buffer ionization (discharge-off) and (b) solvent-mediated $\mathrm{CI}$ (discharge). Amount injected: $500 \mathrm{ng}$.

strong influence on the ion abundance in the TSP spectra.

It has been demonstrated that the combination of different mass spectrometry ionization techniques such as APCI, CAD, ${ }^{252} \mathrm{Cf}-\mathrm{PD}, \mathrm{ESI}, \mathrm{FAB}$, and TSP is useful for the elucidation of fragmentation mechanisms in TSP mass spectra. These techniques were applied to the analysis of phenylureas and anilides. The fragmentation and degradation reactions studied include reductive dehalogenations, nucleophilic substitutions, and thermal decompositions. The information obtained from this comparative study should facilitate the identification, quantification, and confirmation of pesticide residues in complex aqueous matrices by TSP LC-MS.

\section{Acknowledgments}

Grateful acknowledgment is made to Dr. Hans-Martin Schiebel from the mass spectrometric facility of the Technische Universität Braunschweig, Germany, where the FAB studies were carried out. We are also grateful to Dr. Wolfgang Dreher (BASF AG,
Limburgerhof, Germany) and Dr. Winfried Wagner-Redeker (Finnigan MAT, Bremen, Germany) for technical support during APCI and ESI experiments, to Dr. Manfred Raida (Institut für Peptidforschung, Hannover, Germany) for the ${ }^{25 ?}$ Cf-PDMS experiments and to Sylvia Kramer and Dr. Jochen Schmidt (Solvay Deutschland, Hannover, Germany) for the comparative experiments with the Finnigan MAT TSP source. The authors wish to thank Ference Toth for his assistance during on-line enrichment experiments. This research was supported by funds from the Bundesministerium für Forschung und Technologie (Bonn, Germany).

\section{References}

1. U.S. Environmental Protection Agency, National Survey of Pesticides in Drinking Water Wells, Phase I Report: 1990; Office of Water and Office of Pesticides Programs, U.S. Government Printing Office: Washington, DC, 1990; EPA-570/990-015.

2. Commission of the European Communities, EEC Drinking Water Guideline; 80/779/EEC, EEC No. L229/11-29; EEC: Brussels, August 30th, 1980. 
3. Böhm, H. B.; Feltes, J.; Volmer, D.; Levsen, K. J. Chromatogr. 1989, 478, 399-407.

4. De Kok, A.; Hienstra, M.; Brizkman, U. A. Th. J. Chronatogr. 1992, 623, 265-276.

5. Bellar, T. A.; Budde, W. L. Anal. Chem. 1988, 60, 2076-2083.

6. Volmer, D; I evsen, K.; Wïnssh, G. J. Chromatogr., 1994, 660, 231-248.

7. Volmer, D.; Preiss, A.; Levsen, K.; Wünsch, G. J. Chromatogr. 1993, 647, 235-259.

8. Barceló, D. Biomed. Environ. Mass Spectrom. 1988, 17, 363-369.

9. Farran, A.; De Pablo, J.; Barceló, D. J. Chromatogr. 1988, 455, 163-172.

10. Barceló, D. Org. Mass Spectrom. 1989, 24, 219-224.

11. Voyksner, R. D. In Applications of New Mass Spectrometry Techniques in Pesticide Chemistry; Rosen, J. D., Ed.; Wiley: New York, 1987; p 146.

12. Jones, T. L.; Betowsky, L. D.; Yinon, J. In Liquid Chromatography/Mass Spectrometry. Applications in Agricultural, Pharmaceutical, and Environmental Chemistry; Brown, M. A., Ed.; ACS Symposium Series 420; American Chemical Society: Washington, DC, 1990, p 62 .

13. Voyksner, R. D.; McFadden, W. H.; Lammert, S. A. In Applications of New Mass Spectrometry Techniques in Pesticide Chemistry; Rosen, J. D., Ed.; Wiley: New York, 1987; p 247.

14. Barceló, D.; Durand, G.; Vreeken, R. J.; De Jong, G. J.; Lingeman, H.; Brinkman, U. A. Th. J. Chromatogr. 1991, 553, 311-328.

15. Vreeken, R. J.; Van Dongen, W. D.; Ghijsen, R. T.; Brinkman, U. A. Th. Int. J. Environ. Aral. Chem., 1994, 54, 119-145.

16. Behymer, T. D.; Bellar, T. A.; Budde, W. L. Anal. Chem. 1990, $62,1686-1690$.

17. Pleasance, S.; Anacletor J. F.; Baily, M. R.; North, D. H. J. Am. Soc. Mass Spectrom. 1992, 3, 378-397.

18. Lin, H.; Voyksner, R. D. Anal. Chem. 1993, 65, 451-456.

19. Chiu, K. S.; Van Langenhove, A.; Tanaka, C. Biomed. Enoiron. Mass Spectrom. 1989, 18, 200-206.

20. Niessen, W. M. A.; Van der Hoeven, R. A. M.; De Kraa,
M. A. G.; Herremans, C. E. M.; Tjaden, U. R.; Van der Greef, J. I. Chromatogr. 1989, 478, 325-338.

21. Niessen, W. M. A.; Van der Greef, J. Liquid Chromatography-Mass Spectrometry. Principles and Applications; Marcel Dekker: New York, 1992; p 403.

22. Lias, S. G.; Bartness, J. E.; Liebman, J. F.; Holmes, J. L.; Levin, R. D.; Mallard, W. G. J. Phys. Chem. Ref. Data 1988, 17(suppl 1), 23.

23. Hartman, K. N.; Lias, S.; Ausloos, P.; Rosenstock, H. M.; Schroyer, S. S.; Schmidt, C.; Martinsen, D.; Milne, G. W. A. A Compendium of Gas Phase Basicity and Proton Affinity Measurements; NBSIR 79-1777; National Bureau of Standards: Washington, DC, 1979.

24. Tamiri, T.; Zitrin, S. Biomed. Environm. Mass Spectrom. 1987, 14, 39-46.

25. Cairns, T.; Siegmund, E. G. In Liquid Chromatography/Mass Spectrometry. Applications in Agricultural, Pharmaceutical, and Environmental Chemistry; Brown, M. A., Ed,; ACS Symposium Series 420; American Chemical Society: Washington, DC, $1990, \mathrm{p} 40$.

26. McFadden, W. H.; Lammert, S. A. J. Chromatogr. 1987, 385, 201-211.

27. Shalaby, L. M.; Bramble, F. Q.; Lee, P. W. J. Agric. Food Chem. 1992, 40, 513-517.

28. Volmer, D.; Levsen, K.; Engewald, W. Vom Wasser, 1994, 82, 335-364.

29. Madhusudanan, K. P.; Murthy, V. S. J. Chem. Soc. Perkin Trans. 2 1989, 9, 1255-1260.

30. Budzikiewicz, H. Org. Mass. Spectrom. 1988, 23, 561-565.

31. Schiebell, H.-M.; Schulze, P.; I eibfritz, D.; Jastorf. B.; Maurer, K. H. Biomed. Mass Spectrom. 1985, 12, 170-180.

32. Musser, S. M.; Kelley, J. A. Org. Mass Spectrom. 1993, 28, 672-678.

33. Siegel, M. M.; McGahren, W. J; Ellestad, G. A. In Mass Spectrometry in the Analysis of Large Molecules; McNeal, C. J., Ed.; Wiley: New York, 1986; p 207.

34. Yang, Y.-M.; Fales, H. M.; Pannell, L. Anal. Chem. 1985, 57, 1771-1772. 